\title{
Is there a risk of growing fast? The relationship between organic employment growth and firm exit
}

\section{Haibo Zhou ${ }^{1, *}$ and Peter van der Zwan ${ }^{2}$}

${ }^{1}$ Department of Entrepreneurship, Marketing and Management Systems, Nottingham University Business School, University of Nottingham Ningbo China, 199 Taikang East Road, University Park, Ningbo 315100, China. e-mail: haibo.zhou@nottingham.edu.cn and ${ }^{2}$ Department of Business Studies, Leiden Law School, Leiden University, Steenschuur 25, 2311 ES Leiden, The Netherlands. e-mail: p.w.van.der.zwan@law.leidenuniv.nl

\begin{abstract}
Growing firms are the drivers of economic dynamics. While the existing literature often focuses on the average effect of growth on firm survival, we investigate how survival rates vary across the growth distribution using Dutch longitudinal firm-level data (1999-2012). We theorize and find a Ushaped relationship between organic employment growth and subsequent exit due to firm death in various model specifications. Low positive growth increases survival, too much growth could be harmful for some subgroups of firms, and the steepness of the U-shape depends on firm age, size, and industry.
\end{abstract}

JEL classification: L21, L25, L26, M21

\section{Introduction}

Firm growth and firm survival are reoccurring and central topics in the entrepreneurship literature (McKelvie and Wiklund, 2010; DeTienne and Chirico, 2013) because they are important drivers of the dynamics of economic markets. Firm survival—or, rather, its opposite, firm exit-has two opposite economic effects. On the one hand, firm exit has various negative consequences, including financial costs (such as unpaid bills and wages), unemployment, and the depreciation of (firm-specific) human capital. On the other hand, firm exit is a necessary aspect of creative destruction (Schumpeter, 1934), where underperforming enterprises are replaced by new and innovative enterprises. Firm growth is considered the essence of entrepreneurship (Sexton and Smilor, 1997) and an indicator of a firm's success (Schutjens and Wever, 2000). Growing firms, in particular high-growth firms (HGFs), are the main drivers of job creation within the economy (Birch et al., 1995; Davidsson and Henrekson, 2002; Acs and Mueller, 2008; Henrekson and Johansson, 2010; Acs, 2011). In addition, HGFs provide employment opportunities to individuals who have problems entering the labor market (Coad et al., 2014b). The internal dynamics (i.e., entry, growth, decline, and exit) of such firms is thus at the core of economic dynamics (Coad and Hölzl, 2010). Therefore, promoting high-growth small- and medium-sized enterprises has become an important objective of policy makers (European Commission, 2010; OECD, 2010).

Recently, researchers have paid attention to the growth persistence of HGFs (Coad, 2007; Capasso et al., 2009; Coad and Hölzl, 2009; Daunfeldt and Halvarsson, 2015; Hölzl, 2014) and the performance of HGFs after their fast- 
growth period (Acs and Mueller, 2008; Parker et al., 2010). Many of these studies have found that the growth path of HGFs is not persistent but often stabilizes or even declines (Coad et al., 2014a). Importantly, these studies are restricted to surviving firms. This raises the question of whether a period of (high) growth can also be followed by an exit or whether growing firms realize higher survival rates than firms that do not grow (Daunfeldt and Halvarsson, 2015). In other words, the present paper focuses on the relationship between a firm's growth rate and its subsequent chances of survival. To this end, we investigate how the probability of exit due to firm death varies across the growth distribution-ranging from a large decline to substantial growth in terms of the number of employees. By incorporating the entire growth distribution and deviating from current practice focusing on the average effect of firm growth, we allow for a nonlinear relationship between firm growth and exit due to firm death. We thus recognize that too much growth can also be harmful beyond a certain growth threshold value.

Empirical research about the relationship between growth and survival has led to inconclusive evidence. Some studies find a positive autocorrelation of firm growth, where firm growth stimulates future growth and enhances the survival of the firm (e.g., Eisenhardt and Schoonhoven, 1990; Bottazzi and Secchi, 2003), thereby reducing the probability of exit. Other studies find the opposite, indicating that growth can lead to the decline of the firm (e.g., Coad, 2007; Capasso et al., 2009; Coad and Hölzl, 2009), thereby increasing the probability of exit. In addition, a few studies do not find a significant relationship between growth and survival at all (e.g., Oliveira and Fortunato, 2008). There are at least two reasons underlying these mixed findings. First, the phenomenon of "comparing apples with oranges" indicates that the measure of firm growth matters in empirical work (Shepherd and Wiklund, 2009). Empirical results might be dependent on the growth indicator (e.g., sales versus employment; Weinzimmer et al., 1998), the mode of firm growth (e.g., acquired vs. organic growth), or the calculation of firm growth (McKelvie and Wiklund, 2010). Second, and relevant for the present study, positive growth is generally considered a beneficial antecedent of the survival and profitability of a firm (Capon et al., 1990; Eisenhardt and Schoonhoven, 1990; Bottazzi and Secchi, 2003). This prevailing view on growth and survival has led researchers to emphasize the disadvantage of a deficient rate of growth. However, according to the "Too-Much-of-a-Good-Thing" (TMGT) effect (Pierce and Aguinis, 2013), beneficial antecedents might cause undesired outcomes after reaching a context-specific inflection point. Thus, there is a need for a balanced view between deficiency and excess, while taking account of the contextspecific character of the inflection point of firm growth (Pierce and Aguinis, 2013). The TMGT effect may explain the mixed empirical results in the existing literature about the relationship between growth and survival.

Echoing the current interest in HGFs (Coad et al., 2014a), we aim to answer whether a period of (high) growth can also be followed by an exit by investigating a possible curvilinear (U-shaped) relationship between organic employment growth and subsequent exit due to firm death. ${ }^{1}$ The present study adds to the existing literature on firm growth and survival in at least three ways. The first contribution relates to the sample under investigation. Compared with most studies focusing on the growth path of HGFs, we do not restrict our sample to surviving firms. We use a census-based rather than a sample-based dataset and, hence, expect survivorship bias to play a minimal role in our study.

The second contribution is that, while existing studies on the relationship between firm growth and survival often focus on the average effect of growth, we examine how firm exit rates vary across the distribution of growth rates and investigate a possible nonlinear relationship between growth and survival. To hypothesize the U-shape, we combine a theoretical lens based on the industrial organization literature with Penrose's theory of the growth of the firm (Penrose, 1995), thereby incorporating the TMGT effect (Pierce and Aguinis, 2013). On the one hand, firm growth can accumulate resources, which strengthen a firm's competitive advantage (Penrose, 1995). Based on the principles of firm size, firm growth and the minimum efficient scale (MES) in the industrial organization literature (see also Section 2), firms that are initially small need to grow more rapidly to reach the cost-efficient production level to reduce the probability of exit (Dunne and Hughes, 1994; Sutton, 1997; Audretsch et al., 2004; Yasuda, 2005). On the other hand, firm growth involves internal changes in resources and capabilities (Penrose, 1995). Specific resources, capabilities, and organizational compositions are associated with each phase of firm growth to make transitions between different phases successful (Greiner, 1972, 1998; Levie and Lichtenstein, 2010; Sirmon et al., 2011). Adjustment costs often occur during transitions (Penrose, 1995; Lockett et al., 2011). For the group of HGFs that

1 We acknowledge that firm exit does not necessarily equate to failure, and underperforming firms might not exit despite poor performance (DeTienne et al., 2008; Wennberg et al., 2010). Therefore, we only use exit status as a proxy for survival without claiming whether exit due to firm death represents the failure or success of a firm. 
grow excessively in a short period, the benefit of growing quickly to survive is likely to be overtaken by the adjustment costs associated with the organizational complexity caused by rapid growth. This type of argumentation, of why firm growth may be good for survival initially but harmful for survival under more rapid growth conditions, corresponds with the argumentation put forward in Haans et al. (2016). The positive effect of growth eventually levels off, and the negative effect increases quickly as adjustment costs start to dominate the relationship between growth and survival. Hence, a U-shaped relationship is expected between firm growth and firm exit. The second part of the U-shape is related to the so-called "curse of fast growth" or "growth setback" due to the deficiency of the "right" resources, capabilities, and organizational structure (Hambrick and Crozier, 1985; Penrose, 1995; Garnsey et al., 2006; Gjerløv-Juel and Guenther, 2012; Hölzl, 2014). This deficiency may occur once a firm's growth rate reaches an inflection point after which growth leads to an undesired outcome (Pierce and Aguinis, 2013), that is, exit due to firm death in the present case.

The third contribution relates to the context-specific character of the inflection point in terms of the TMGT effect (Pierce and Aguinis, 2013). The dataset allows us to explore under which circumstances firm growth reaches an inflection point after which growth increases the exit probability. Earlier studies in the area of firm growth and survival tend to focus on the youngest or smallest firms or on a few specific industries. We consider how the relationship between growth and exit differs along the dimensions of firm age, firm size, and industry, thus providing a more complete picture of the growth-exit relationship.

We investigate the relationship between growth and exit using census-based data from the Dutch Business Register (“Algemeen Bedrijven Register") from Statistics Netherlands for the period of 1999-2012. The empirical results of discrete-time proportional hazard analyses reveal a U-shaped relationship between organic employment growth in the recent past and subsequent exit due to firm death. Although the results and the steepness of the U-shape depend on the model formulation and the growth measure used for the analysis, we generally find that (i) exit probabilities are high for firms that experience contraction in terms of the number of employees, and the probability of exit decreases rapidly once negative growth approaches zero; (ii) growing modestly is beneficial in terms of survival rather than experiencing zero growth; and (iii) growth is harmful for some subgroups of fast-growing enterprises (including HGFs). Hence, for some subgroups of firms, the probability of exit due to firm death increases after an inflection point of firm growth (the TMGT effect), and hence, there is a risk of growing fast. We point to different U-shapes depending on a firm's size, age, and industry.

The remainder of the paper is organized as follows: The next section develops our hypothesis on a curvilinear (Ushaped) relationship between organic employment growth and exit due to firm death. Subsequently, the data and the research methodology are presented. The estimation results are presented next, followed by a discussion and conclusion.

\section{Theory and hypothesis}

There is a large stream of literature focusing on the relationship between firm growth and firm survival (or firm exit). Recent studies have emphasized the persistence of firm growth among HGFs; however, empirical results from these studies are rather mixed (Gjerløv-Juel and Guenther, 2012; Coad et al., 2013; Delmar et al., 2013; Hölzl, 2014). While reviewing these studies, we found that most of the theoretical rationales on firm growth and survival are either using an industrial organization lens or taking the perspective of organization theory. To develop our hypothesis on the possible curvilinear (U-shaped) relationship between growth and exit, we build our arguments upon these two theoretical lenses.

\subsection{Firm growth and survival: view from the industrial organization literature}

The industrial organization literature focuses on Gibrat's law, a law of proportionate effect Audretsch et al., 2004) that extensively discusses the relationship between firm size and firm growth (Daunfeldt and Halvarsson, 2015). Gibrat's law assumes that the growth rate of a firm is independent of its initial size, so the probability of a given growth rate (during a specific time interval, within a specific industry) is identical for all firms. However, empirical studies do not find supporting evidence (Becchetti and Trovato, 2002). Several studies indicate that smaller and younger firms show higher growth rates than their larger and older counterparts. This finding has been widely supported by studies based on cross-country comparisons or cross-industry comparisons (Dunne and Hughes, 1994; 
McPherson, 1996; Almus and Nerlinger, 2000; Goddard et al., 2002; Bottazzi and Secchi, 2003; Calvo, 2006). The negative relationship between firm size and firm growth has been related to the concept of the MES. ${ }^{2}$ The decrease in a firm's growth rate along with its increased size may be a consequence of the firm's aim to reach the optimal scale of production that allows it to survive (Dunne and Hughes, 1994; Sutton, 1997). Small firms tend to operate on a production scale below the MES and grow relatively rapidly to achieve this MES (Audretsch et al., 2004; Yasuda, 2005).

Moreover, the positive relationship between firm size and the likelihood of survival is consistently found in empirical studies (Dunne et al., 1989; Audretsch and Mahmood, 1994, 1995; Mata and Portugal, 1994; Mitchell, 1994; Geroski, 1995; Haveman, 1995; Sharma and Kesner, 1996; Sutton, 1997). The theoretical explanation of this positive relationship is grounded in the model of noisy selection (Jovanovic, 1982; Pakes and Ericson, 1998). The central feature of the model is the learning process regarding the relative efficiency gained from actual market experience. Hence, the true level of the managerial competence of entrepreneurs is only discovered subsequent to their entry into the industry. Firms that are more efficient than others expand their scale of productive capacity, whereas less efficient firms will remain small and suboptimal, which may ultimately lead to exit (Agarwal and Audretsch, 2001). Firm size plays a role here in that larger firms are closer to the MES, which is needed to operate efficiently in a market, and larger firms have fewer cost disadvantages. Therefore, compared with smaller firms, larger firms are less vulnerable and are more likely to survive (Audretsch and Mahmood, 1994, 1995).

Two main stylized facts emerge from the industrial organization literature: firm size is negatively related to firm growth and positively related to firm survival. Smaller firms will show higher average growth rates and lower survival rates than larger firms. This suggests that firm growth accompanies firm exit, that is, a negative relationship between growth and survival can be expected. This negative relationship does not imply a causal effect of firm growth on firm survival but merely reflects that firm growth and firm survival have an opposite relationship with firm size. Note that this negative relationship only applies to the aggregated level of size classes but not to the level of the individual firm. ${ }^{3}$ At the level of the individual enterprise, a different relationship between firm growth and firm survival may exist, where firm survival at time $t$ may be partially dependent on firm growth prior to $t$. For instance, the models of noisy selection suggest that higher employment growth rates may increase a firm's survival rate as long as the firm is operating below its MES.

Putting the aforementioned arguments together regarding the size-growth and size-survival relationships, we conclude that smaller firms are more likely to exit than larger firms, whereas smaller firms tend to grow more quickly to survive. Once these small firms have become larger, they are less likely to exit. Thus, we argue that a higher growth rate decreases the probability of exit due to firm death. ${ }^{4}$

\subsection{Firm growth and survival: the perspective of organization studies}

In the organization and management literature, Penrose's theory of the growth of the firm provides an overarching framework to explain the process of firm growth (Penrose, 1995). The theory considers firm growth a result of a process of internal changes in resources and capabilities that leads to an increase in size accompanied by changes in firm characteristics (Penrose, 1995; Naldi and Davidsson, 2014). Firm growth is path-dependent, as past growth accumulates resources that can be used for future growth and strengthens the competitive advantage of the firm (Penrose, 1995). Therefore, firm growth is always desirable because it is positively correlated with the survival and profitability of a firm, and low growth rates may increase the probability of firm exit (Capon et al., 1990; Eisenhardt and Schoonhoven, 1990; Bottazzi and Secchi, 2003). The prevailing view considering firm growth a beneficial antecedent for survival is also supported by earlier findings in the industrial organization literature. For instance, Dunne and Hughes (1994), using asset growth, find an inverse U-shaped relationship between exit and firm size; that is, the

2 The MES is the minimum scale at which cost-efficient production is possible.

3 The aggregate statistics of growth rates and survival rates are based on different samples: average growth rates are based on existing or surviving enterprises within each size class, while average survival rates are based on all enterprises.

4 Much of the literature about firm growth focuses on firms that experience positive growth. However, our dataset also includes firms with negative or zero growth, and hence, such firms are also included in the analyses. For the subset of firms with negative employment growth, one could also hypothesize a negative relationship between growth and firm exit, and this relationship between decline and exit could then also be part of the overall U-shape between growth and exit. Note that there is a tautologous aspect here in that firms that shrink rapidly implicitly have a high likelihood of exit. 
probability of exit increases for smaller firms while it decreases for larger firms. These observations again imply that firm growth may reduce the probability of firm exit.

While firm growth creates resources that a firm can use for future growth (Penrose, 1995), transforming new resources into productive opportunities involves adjustment costs, such as the time and effort required to integrate new employees into the firm (Penrose, 1995; Lockett et al., 2011). Managerial capabilities are considered important to make this process effective (Penrose, 1995). These adjustment costs and limited managerial capabilities may result in a "growth setback" or "growth interruption" during the process of firm growth (Garnsey and Heffernan, 2005; Garnsey et al., 2006).

In a similar vein, stage models focus on the generic problems that organizations encounter during the growth process (Davidsson et al., 2005). Although the number of stages is debatable, it has been empirically shown that firms tend to operate in a definable state for some period of time (Levie and Lichtenstein, 2010). The merit of stage models is that they make observations of firms' internal dynamics and associated changes in resources and capabilities (e.g., Garnsey et al., 2006). Specific resources, capabilities, and organizational compositions are orchestrated in each phase of the firm's life cycle to make the transition between different phases successful, which ultimately leads to growth (Greiner, 1972, 1998; Levie and Lichtenstein, 2010; Sirmon et al., 2011). This suggests the importance of different managerial actions to resource orchestration during the firm growth process (Helfat et al., 2007; Sirmon et al., 2007, 2011).

The view on "growth setback" or "growth interruption" has been supported by empirical studies on the growth persistence of HGFs. Although these studies produce mixed results (Gjerløv-Juel and Guenther, 2012; Coad et al., 2013; Delmar et al., 2013; Hölzl, 2014), a general tendency is in favor of a negative autocorrelation in annual growth, particularly within the group of small HGFs (Coad, 2007; Coad and Hölzl, 2009; Capasso et al., 2009). HGFs are essentially "one hit wonders" (Daunfeldt and Halvarsson, 2015; Hölzl, 2014) and are more likely to suffer from the "curse of fast growth" (Hölzl, 2014). This is because HGFs cannot cope with rapid growth due to their deficiency of the "right" resources, capabilities, and organizational structure (Hambrick and Crozier, 1985; Penrose, 1995; Garnsey et al., 2006; Gjerløv-Juel and Guenther, 2012; Hölzl, 2014). In addition, the experience of succeeding in rapid growth may make owner-managers of HGFs "convinced of their wisdom" regardless of the turbulent environment and new competitors (Hambrick and Crozier, 1985: 38). On the basis of these arguments, we conclude that a higher growth rate increases the probability of exit due to firm death because the adjustment costs of transforming new resources into productive opportunities dominate the benefits of growing quickly to survive.

\subsection{Our hypothesis: a U-shaped relationship between firm growth and firm exit}

Following the discussion from our adopted theoretical lenses, we argue that deficient and excessive rates of firm growth do not seem to be desired because they are associated with an increased probability of exit. This observation is in line with the argument of the TMGT effect (Pierce and Aguinis, 2013), that is, an ordinarily beneficial antecedent might cause undesired outcomes once it exceeds an inflection point. To theorize the U-shaped relationship between firm growth and exit, we follow the additive benefit/cost arguments as suggested by Haans et al. (2016).

On the one hand, firm growth is beneficial for the survival of the firm. This is particularly important for smaller and younger firms, which tend to operate on a production scale below the MES and grow more quickly than their larger counterparts to reach the cost-efficient production level to survival (Dunne and Hughes, 1994; Sutton, 1997; Audretsch et al., 2004; Yasuda, 2005). The systematic decrease in a firm's growth rate along with its increased size may be a consequence of the firm's aim to reach the optimal scale of production that allows the firm to survive (Dunne and Hughes, 1994; Sutton, 1997). Researchers who have studied firm growth for different size classes suggest that Gibrat's law of size independence only holds for firms above a certain size threshold, of, for instance, 400 employees (Bigsten and Gebreeyesus, 2007).

On the other hand, a firm's deficiency of the "right" resources, capabilities, and organizational structure caused by excessive firm growth increases the adjustment costs of transforming new resources into productive opportunities for future growth. This is supported by a general tendency in favor of a negative autocorrelation in annual growth, particularly within the group of small HGFs (Coad, 2007; Coad and Hölzl, 2009; Capasso et al., 2009). While the positive effect of firm growth on survival increases at a decreasing rate and eventually levels off, the negative effect of firm growth on survival rises quickly with rapid growth. This results in an inverted U-shaped relationship between firm growth and firm survival and fits with the second argumentation of the general framework in Haans et al. (2016). In other words, 
Table 1. Total number of firms and number of firms that exit due to firm death (2003-2012)

\begin{tabular}{llllllllllll}
\hline Year & 2003 & 2004 & 2005 & 2006 & 2007 & 2008 & 2009 & 2010 & 2011 & 2012 & Total \\
\hline $\begin{array}{l}\text { Number of } \\
\text { observations }\end{array}$ & 585,666 & 605,918 & 634,779 & 522,196 & 522,658 & 521,352 & 493,674 & 579,041 & 626,584 & 706,531 & $5,798,399$ \\
$\begin{array}{c}\text { Exit due to } \\
\text { firm death }\end{array}$ & 40,014 & 41,028 & 39,864 & 38,708 & 40,342 & 43,113 & 34,243 & 37,300 & 37,400 & 46,776 & 398,788 \\
\begin{tabular}{l} 
In \% \\
\hline
\end{tabular} & 6.83 & 6.77 & 6.28 & 7.41 & 7.72 & 8.27 & 6.94 & 6.44 & 5.97 & 6.62 & 6.88 \\
\hline
\end{tabular}

we assume that high growth in the recent past decreases the probability of firm exit initially but increases the probability of firm exit when growth exceeds an inflection point. ${ }^{5}$ We thus suggest the following hypothesis:

Hypothesis: A U-shaped relationship exists between organic employment growth and subsequent exit due to firm death.

\section{Data and methods}

\subsection{Data source and sample}

\subsubsection{Data source}

We use the data from the Dutch Business Register ("Algemeen Bedrijven Register") from Statistics Netherlands for the period of 1999-2012. This data source contains all firms that are registered in the Netherlands, and it therefore comprises a census-based rather than a sample-based dataset. Each observation in the Dutch Business Register represents a single enterprise in a particular year (we have firm-year data), and in our case, the longitudinal dataset follows each registered firm for a maximum period of 14 years. We know in which year firms entered the database (date of registration), whether certain mutations took place during the years (e.g., merging or acquisition, or other administrative mutations), and whether an exit has taken place (and the type of exit). This also means that a firm is followed from its inception onward and that an exit event is always included in the dataset.

\subsubsection{Sample}

Our primary interest is the relationship between organic employment growth and exit due to firm death. We hence confine our sample based on these variables of interest. Table 1 provides an overview of the number of observations in our database along with the distribution of the variable exit due to firm death. On average, we use more than 500,000 observations per year. Table 1 is based on the estimation sample that will be presented below, that is, with the annualized (nonlogarithmic) 3-year growth rate measure included (we include a lagged measure throughout; details about measurement follow below). Note that Table 1 shows data from 2003 onward: to analyze firm exit in 2003, we use information about the number of employees from the years 1999 to 2002.

Table 1 shows that, on average, $6.88 \%$ of all observations in our dataset correspond to exit due to firm death events. Other calculations (not shown here) show that an exit due to firm death is the main reason for exit and that other exit reasons represent only a marginal fraction of the total dataset.

The number of firms in the Netherlands that are included in the original dataset from Statistics Netherlands is greater than the numbers presented in Table 1. A first obvious reason for this reduced sample is that Table 1 excludes firms that exited due to reasons other than firm death. Therefore, firms in our sample have two possible statuses at year $t$, that is, either exit due to firm death or it is still in existence (continuation). Second, we require information on lagged organic employment growth in the recent past. Therefore, we excluded from the sample enterprises that had not (yet) existed for at least 4 years, such as new entries and enterprises that entered and exited in a single year. Note that this may introduce survivorship bias in our analysis. We therefore also perform our analyses with 1-year growth rates rather than 3-year growth rates, and we perform analyses correcting for sample selection below. Third, there

5 Note that the prior literature does not provide us with arguments of where the hypothesized inflection point lies exactly, and hence, we also abstain from formulating such an expectation in our hypothesis. 
may be missing information for one of the (control) variables in our study, such as the year of the exit or the reason for the exit.

\subsection{Measurement}

\subsubsection{Exit due to firm death}

The dependent variable in the present study is the exit status of enterprises. This variable can take two values: 1 if firm $i$ exits in year $t$ due to firm death and 0 if firm $i$ still exists at the end of year $t$.

For each year, we know whether a firm continued or discontinued its activities. In the case of the continuation of activities, the dataset distinguishes between the following "events" (or mutations): (i) continuation of activities where a part of the business was separated from the business, (ii) continuation of activities where the business took over or acquired another business, (iii) continuation of activities where the business underwent a restructuring process, and (iv) continuation of activities without any of the events under (i)-(iii) taking place. Nonorganic growth means that a firm continued its activities but that some mutation under (i)-(iii) had taken place.

If nonorganic growth has taken place for a firm, we do not take account of the observations belonging to the firm.

\subsubsection{Firm growth: organic employment growth}

We confine our growth indicator to organic employment growth for three reasons: first, employment growth is a direct indicator of organizational complexity (Kogut and Zander, 1992; Penrose, 1995). As noted by Garnsey et al. (2006), employment growth might be the best growth measure because of its provision of standardized and comparable data on firm expansions. Employment growth is also the standard indicator in studies on firm growth patterns (Garnsey et al., 2006). Second, a practical restriction to our choice is that we do not have the availability of indicators other than employees, such as sales, assets, or profits, in the present dataset. Third, regarding the choice for organic rather than nonorganic growth, firms that grow organically in employment are the primary interest of policy makers due to their contribution to job creation (see also Coad et al., 2016b). ${ }^{6}$

In our analysis, we relate the exit status of an enterprise in year $t$ to the lagged average 3 -year growth rate, that is, the average 3-year growth rate for the year $t-4$ to $t$ - 1 . The 3-year measurement period has been commonly used to measure firm growth (Delmar, 1997). Another reason for this 3-year growth rate is that our sample includes a substantial group of HGFs. Adopting the Eurostat-OECD definition (Eurostat-OECD, 2007), HGFs are defined as firms with an annualized employment growth greater than $20 \%$ during a 3 -year period. ${ }^{7}$

The choice of using the lagged growth rate (based on $t-1$ and $t-4$ ) rather than current growth rate (based on $t$ and $t$-3) is twofold. The first goal is to avoid a biased measurement of the average 3-year growth rate. For instance, suppose that an enterprise exits in July in year $t$. For the calculation of the average 3-year growth rate, this measure of enterprise size (based on 6 months of employment) is then compared with the enterprise size 3 years earlier (based on 12 months of employment), which would not be correct. Second, there is a theoretical argument to include a lag: for firms that exit the market because of their deficiency of the "right" resources, capabilities and organizational structure, it is conceivable that their growth rates stagnate in the final year before they actually exit.

\subsubsection{Firm growth: measurement}

To calculate the lagged average 3-year growth rate, it is possible to use the data from 2003 onward. We focus on relative growth in this study, which is commonly used in the industrial organization literature (Coad and Hölzl,

6 We do not claim that organic growth at the firm level is the only path that leads to aggregate employment gains. Organic growth, for instance, can also be the result of business stealing, which leads to employment losses at a competitor firm. However, such market-level or even aggregate-level information is not available in the present dataset. We acknowledge this limitation in the concluding section of the paper. We thank an anonymous reviewer for pointing this out.

7 The Eurostat-OECD definition of HGFs excludes micro firms with less than ten employees in the starting year. Daunfeldt et al. (2015) criticize this definition, maintaining that micro firms contribute a large share of job creation (De Wit and De Kok, 2014) and are therefore important to include. We follow this argument, and therefore, the present study adopts the Eurostat-OECD definition of HGFs but relaxes the threshold of 10 employees to include micro-HGFs as well. 
2010). An obvious measure is the annualized employment growth rate, defined as $\left[\operatorname{size}_{t-1} / \mathrm{size}_{t-4}\right]^{(1 / 3)}-1$. Size is determined by the number of full-time employees. As an additional measure of relative firm growth, we use the difference in logarithms, which is the best way to measure relative changes according to Törnqvist et al. (1985). It is defined as $\ln \left(\right.$ size $\left._{t-1}\right)-\ln \left(\operatorname{size}_{t-4}\right)$, where $\ln (\cdot)$ is the natural logarithm. ${ }^{8}$

As already indicated above, we also perform analyses where we measure growth on a 1-year rather than a 3-year basis.

We exclude outliers and restrict our independent variable to values between -2 and 2 . Hence, we exclude a very small subset of firms that would drive our results to a large extent because of their very high annualized growth rates of, for example, $300 \%$ or $500 \%$.

\subsubsection{Control variables}

The number of control variables in our dataset is limited. We control for firm size, firm age, industry affiliation, and the regional location of a firm. In the regression models, we include the log of firm size in the previous period. Regarding firm age, we do not impose a restriction on the functional form of the relationship between age and exit due to firm death. Instead of including, for example, firm age and firm age squared, we use dummy variables to distinguish between firms that are 4 years old, 5 years old, and so forth up to 9 years old, 10-14 years old, 15-24 years old, and 25 years or older. (In the model specifications with 1-year growth rates, we also add dummy variables for firms that are 2 and 3 years old.) The oldest age category is used as the reference category. The dataset contains very specific four-digit sector information. We reduce this detailed information to a categorization of 15 industries that are part of the business economy (see Table 3, which is discussed below). Finally, the dataset contains detailed information about a firm's geographic location. We control for this location in a concise way by means of the degree of urbanization. Statistics Netherlands determines the degree of urbanization upon the surrounding address density, defined as the average number of addresses within a $1-\mathrm{km}$ radius in a particular city. Cities are categorized as urbanized when this density exceeds a certain threshold, depending on the year under study. The following cities were classified as urbanized by Statistics Netherlands every year during the period 2003-2012: Amsterdam, Delft, Den Haag, Groningen, Haarlem, Leiden, Leidschendam-Voorburg, Rijswijk, Rotterdam, Schiedam, Tilburg, Utrecht, and Vlaardingen. The variable takes a value of 1 in the case of an urbanized region and a value of 0 when this is not the case.

\subsection{Estimation methodology}

\subsubsection{Hazard model}

Given the nature of our dependent variable, a discrete-time logistic proportional hazard model is used (e.g., Geroski et al., 2010; Cefis and Marsili, 2012). This model can handle time-varying covariates and right-censored observations, as in the present case. Examples of right-censored observations in the present study are firms that are still in existence at the end of 2012.

The discrete-time model is used because duration is a discrete variable: the data are collected on a yearly basis. The model is basically the discrete-time representation of an underlying continuous time proportional hazard model. The functional form for the baseline hazard function is determined to be $\ln (t)$ in the remaining analyses. We considered several alternative specifications for this baseline hazard function, including $t, t^{2}$, and $t^{3}$, but $\ln (t)$ provided the best fit.

\subsubsection{Functional form}

An important part of this study is to determine the functional form of the relationship between the organic employment growth rate and exit due to firm death. Given our hypothesis of a curvilinear relationship, we add a linear and a quadratic term for employment growth to our model specifications and are primarily interested in the parameter estimates of the quadratic term. In addition to the significance of the quadratic term (the first step), there are two other steps to validate the presence of a U-shaped relationship (Haans et al., 2016). The second step refers to the steepness of the slopes at both ends of the growth range. The third step zooms in on the turning point of the U-shape and the associated confidence interval that should lie within the growth range.

8 Sole traders are also included in our sample. Because of their non-negligible presence in the dataset-referring to about $10 \%$ of the observations in our estimation sample - we add 1 to our size variables to maintain these firms in the dataset. 
Table 2. Descriptive statistics for exit due to firm death, growth measures, firm size, and urbanization

\begin{tabular}{lcccc}
\hline Variable & Mean & SD & Minimum & Maximum \\
\hline Exit due to firm death & 0.069 & 0.25 & 0 & 1 \\
Annualized growth (3 year) & 0.009 & 0.14 & -0.92 & 2.00 \\
Logarithmic growth (3 year) & -0.002 & 0.37 & -2.00 & 2.00 \\
Annualized growth (1 year) & 0.019 & 0.26 & -1.00 & 2.00 \\
Logarithmic growth (1 year) & -0.002 & 0.25 & -2.00 & 2.00 \\
Firm size & 1.04 & 0.76 & 0 & 9.86
\end{tabular}

Total number of observations is 5,798,399, except for 3-year logarithmic growth (5,774,323), 1-year annualized (nonlogarithmic) growth (9,180,025), and 1-year logarithmic growth $(9,203,240)$. Annualized growth (3 years) is defined as $\left[\text { size }_{t-1} / \operatorname{size}_{t-4}\right]^{(1 / 3)}-1$. Logarithmic growth (3 years) is defined as $\ln \left(\operatorname{size}_{t-1}\right)$-ln $\left(\right.$ size $\left._{t-4}\right)$. Firm size is defined as $\ln \left(\operatorname{size}_{t-1}\right) . S D=$ standard deviation. The descriptives for the firm age and sector dummies, and for the urban variable, are provided in Table 3 .

Table 3. Probability of exit due to firm death, for firm size, firm age, industry, and urbanization

\begin{tabular}{lll}
\hline Variable & $\%$ in data & $\%$ of exit due to firm death \\
& $(2003-2012)$ & $(2003-2012)$
\end{tabular}

Firm size

$\operatorname{Micro}(\leq 9)$

Small (10-49)

Medium (50-249)

Large ( $\geq 250)$

Firm age (year)

$$
4
$$

$$
5
$$

$$
6
$$$$
7
$$$$
8
$$$$
9
$$

10-14

15-24

$\geq 25$

Industry
(1) Agriculture, hunting, foresting, fishing, mining, quarrying

(2) Manufacturing of food products, beverages, and tobacco

(3) Manufacturing of metals

(4) Manufacturing of chemicals and chemical products

(5) Other manufacturing sectors

(6) Construction

(7) Sale, maintenance, and repair of motor vehicles

(8) Wholesale

(9) Retail trade

(10) Hotels and restaurants

(11) Transport, storage, communication

(12) Financial services

(13) Business and ICT services

(14) Other services (education, health care, recreation, culture)

(15) Other sectors

Urbanization

Urbanized

Not urbanized

$\begin{array}{rr}94.00 & 7.01 \\ 5.01 & 4.99 \\ 0.82 & 3.87 \\ 0.17 & 3.07 \\ & \\ 10.25 & 9.48 \\ 9.47 & 9.01 \\ 7.83 & 7.96 \\ 7.05 & 7.43 \\ 5.59 & 7.12 \\ 5.09 & 6.71 \\ 19.07 & 6.19 \\ 18.52 & 5.49 \\ 17.13 & 5.65\end{array}$

5.43

6.68

$0.53 \quad 6.09$

$0.99 \quad 5.37$

$0.09 \quad 6.84$

$4.38 \quad 6.00$

$11.25 \quad 5.20$

$\begin{array}{ll}3.18 & 5.25\end{array}$

$\begin{array}{ll}7.89 & 7.81\end{array}$

$11.23 \quad 6.80$

$\begin{array}{ll}4.98 & 7.37\end{array}$

$\begin{array}{ll}3.59 & 7.38\end{array}$

$4.09 \quad 9.58$
24.209 .63

$\begin{array}{ll}24.20 & 7.63\end{array}$

$\begin{array}{ll}18.05 & 6.37\end{array}$

$0.11 \quad 5.35$

$\begin{array}{ll}18.79 & 7.66\end{array}$

$\begin{array}{ll}81.21 & 6.70\end{array}$

In this table, a categorical variable for firm size has been used for clarity; the continuous version (see Table 2) is included in the regressions. These numbers are based on 5,798,399 observations. 

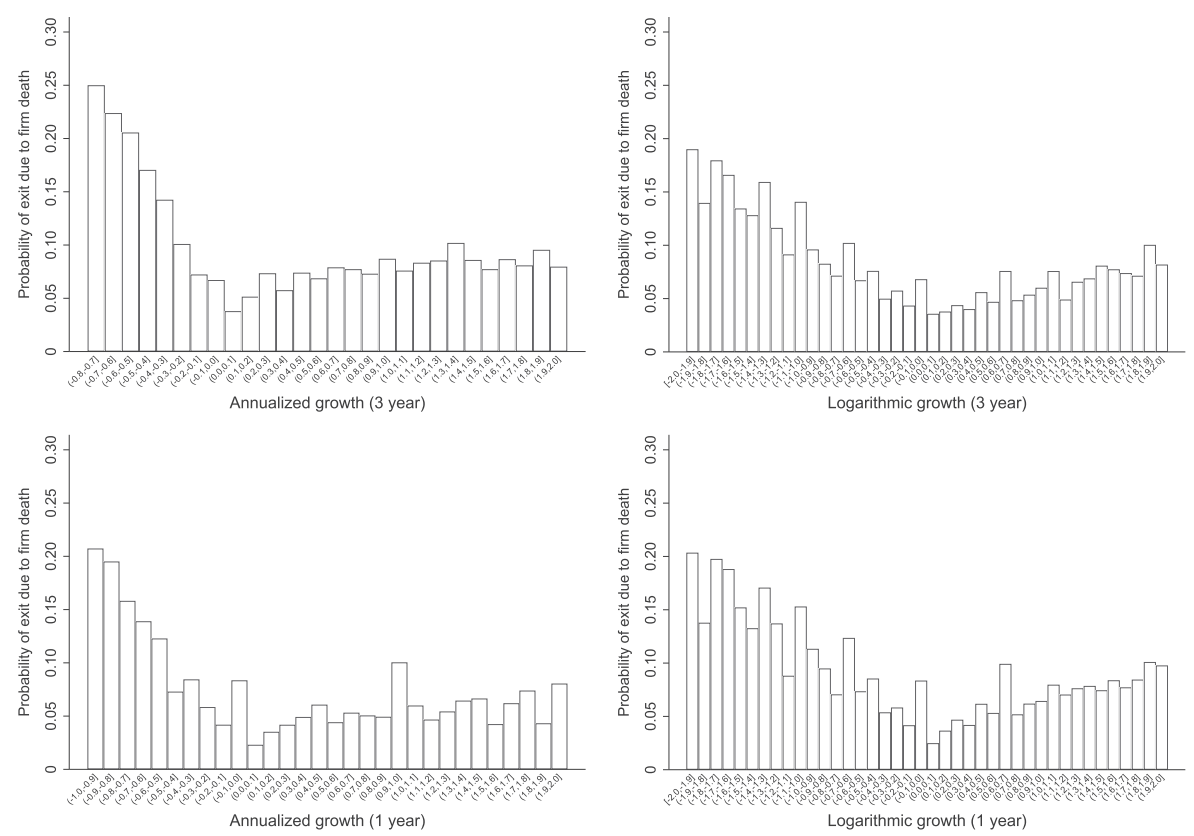

Figure 1. Unconditional relationship between firm growth and exit due to firm death: (A) 3-year annualized growth; (B) 3-year logarithmic growth; (C) 1-year annualized growth; and (D) 1-year logarithmic growth.

As an alternative for the polynomial modeling of the relationship between growth rate and exit, we propose a more flexible form of modeling by means of categorical variables (implemented as an additional analysis). This approach allows us to determine more specifically in which part of the range of the growth variable exit rates are most pronounced.

\subsubsection{Regression equation}

The following equation describes our parameters to be estimated:

$$
\begin{aligned}
& \log \left(P_{i t} /\left(1-P_{i t}\right)\right)=h(t)+\beta_{1} \times \operatorname{growth}(t-1, t-j)+\beta_{2} \times \operatorname{growth}^{2}(t-1, t-j)+\beta_{3} \times \operatorname{size}(t-1)+\beta_{4} \times \operatorname{age}(t)+ \\
& \beta_{5} \times \operatorname{sector}(t)+\beta_{6} \times \operatorname{urban}(t),
\end{aligned}
$$

where $P_{i t}$ takes a value of 1 if exit due to death takes place and 0 for all other observations; the growth variable is relative growth, either in nonlogarithmic (annualized) or in logarithmic form, and $j=2$ or $j=4$ depending on the 1year or 3-year growth measure used.

Furthermore, $h(t)$ is the hazard function and equals the logarithm of the time a firm has been at risk of experiencing an exit, that is, $\ln (t)$. The time between the startup year of the business and the first year of observing the business in the present dataset (1999) has been taken into account in $h(t)$. Size $(t-1)$ equals the logarithm of firm size in the previous year in terms of the number of employees. Age $(t)$ and sector $(t)$ refer to the set of age and sector dummies, respectively, as described above, and the corresponding betas thus refer to a vector of estimated coefficients. Finally, $\operatorname{urban}(t)$ reflects the urban dummy variable.

\subsection{Descriptive statistics}

Table 2 presents some basic descriptive statistics of the dependent variable exit due to firm death, our growth measures of annualized (nonlogarithmic) growth and logarithmic growth ( 1 and 3 years), and firm size. In terms of our annualized (nonlogarithmic) growth measure, we note that (statistics not shown in Table 2) 1,054,774; 3,728,470; and 1,015,155 observations relate to negative, zero, and positive growth over a period of 3 years. These numbers refer to $18.19 \%, 64.30 \%$, and $17.51 \%$, respectively, of the total number of observations $(5,798,399)$. There are 400,680 observations $(6.91 \%$ of the total) with an annualized growth rate of at least $20 \%$ (HGFs according to the Eurostat-OECD definition), which shows that the current database is a suitable source for the present analysis. 
Table 4. Correlation matrix

\begin{tabular}{|c|c|c|c|c|c|c|c|}
\hline Variable & 1 & 2 & 3 & 4 & 5 & 6 & 7 \\
\hline \multicolumn{8}{|l|}{ 1. Exit firm death } \\
\hline 2. Annualized growth (3 years) & $-0.027 * *$ & & & & & & \\
\hline 3. Logarithmic growth (3 years) & $-0.036 *$ & $0.974 * *$ & & & & & \\
\hline 4. Annualized growth (1 year) & $-0.004 * *$ & $0.238 * *$ & $0.214 * *$ & & & & \\
\hline 5. Logarithmic growth (1 year) & $-0.029 * *$ & $0.496 * *$ & $0.520 * *$ & $0.445 * *$ & & & \\
\hline 6. $\operatorname{Ln}$ (firm size) & $-0.052 * *$ & $0.295 * *$ & $0.286 * *$ & $0.098 * *$ & $0.179 * *$ & & \\
\hline 7. Firm age & $-0.042 * *$ & $-0.069 * *$ & $-0.070 *$ & $-0.012 * *$ & $-0.032 * *$ & $0.284 * *$ & \\
\hline 8. Urbanization & $0.015 * *$ & $0.004 * *$ & $0.002 * *$ & $0.002 *$ & -0.000 & $-0.014 * *$ & $-0.037 * *$ \\
\hline
\end{tabular}

$* \mathrm{P}<0.0001$

$* \mathrm{P}<0.001$. Firm age has been added as a continuous variable in this table. The correlations are based on 5,798,399 observations.

While the mean firm size is 1.04 (in logarithms; $\mathrm{SD}=0.76$ ) in the total sample, it is $0.89(\mathrm{SD}=0.69)$ when exit takes place in the next period and $1.05(\mathrm{SD}=0.77)$ when the firm continues to exist in the next period. Because we added 1 to the firm size variable to take account of the large fraction of sole traders (see also below and footnote 8), we also display the nonlogarithmic firm size here. The mean size is 4.65 ; when exit takes place, it is 3.02 , and when no exit takes place, it is 4.77 .

Figure 1 focuses on the unconditional relationship between firm growth and firm exit. The histograms show the probability of firm exit for various subgroups of the growth variables (in intervals of 10 percentage points). The relationship between growth and exit is shown for annualized (nonlogarithmic) 3-year growth (graph A), logarithmic 3year growth (graph B), annualized 1-year growth (graph C), and logarithmic 1-year growth (graph D). There are three broad observations based on the histograms in Figure 1. First, the highest probabilities of exit can be found for those firms that experience declines in terms of the number of employees. Second, the lowest probabilities of exit can be observed for the growth categories $(0 ; 0.1)$ and $(0.1 ; 0.2)$. Hence, firms that grow between 0 (excluding 0 ) and $20 \%$ on a 1-year or 3-year basis have lower probabilities of exit than firms that grow more rapidly, that experience stagnant growth (growth of 0), or that experience a decline. Third, we see an increase in the probability of exit due to firm death for increasing growth rates, although the degree of this increase depends on the measure in use. All in all, the histograms in Figure 1 tend to confirm the U-shaped pattern between firm growth and the probability of exit due to firm death, where the pattern is present more dominantly for logarithmic growth than for annualized (nonlogarithmic) growth.

Table 3 takes a closer look at the distribution of the dependent variable for various categories of the variables firm size, firm age, industry, and urbanization. We again use the sample here that is used for our annualized (nonlogarithmic) 3-year growth measure. The first column with numbers in Table 3 shows the prevalence rate of each category, and the final column presents the probability of exit due to firm death for each category.

Table 3 shows that exit rates decrease with firm size, from $7.01 \%$ for micro firms (up to 9 employees) to $3.07 \%$ for large firms (at least 250 employees). The exit rates also decrease with firm age. The exit rates range from $9.48 \%$ for the youngest firms to $5.65 \%$ for the firms that have been in existence for at least 25 years. Note that the youngest firms in Table 3 are 4 years old (because we use the 3-year growth measure in Table 3). The probabilities of exit for firms that have been in existence for 2 and 3 years are $12.46 \%$ and $11.15 \%$, respectively. Finally, exit rates due to firm death are, on average, highest in the financial services sector $(9.58 \%)$ and lowest in manufacturing of metals $(5.37 \%)$, sales, maintenance, repair of motor vehicles $(5.25 \%)$, and construction $(5.20 \%)$.

Table 4 shows the correlation coefficients for all variables under investigation; potential concerns for multicollinearity are not detected.

\section{Results}

\subsection{Regression results: is there an inflection point?}

We perform discrete-time logistic proportional hazard regressions with exit due to firm death as the dependent variable. The results are shown in Table 5. Models 1 and 2 show the results for the 3 -year growth rates, whereas Models 3 and 4 focus on the 1-year growth rates for annualized (nonlogarithmic) and logarithmic growth. 
Table 5. Regression results discrete-time logistic proportional hazard models

\begin{tabular}{|c|c|c|c|c|c|c|c|c|}
\hline & \multicolumn{4}{|l|}{ 3-year growth } & \multicolumn{4}{|l|}{ 1-year growth } \\
\hline & \multicolumn{2}{|c|}{ Annualized growth (1) } & \multicolumn{2}{|c|}{ Logarithmic growth (2) } & \multicolumn{2}{|c|}{ Annualized growth (3) } & \multicolumn{2}{|c|}{ Logarithmic growth (4) } \\
\hline & Coeff. & SE & Coeff. & SE & Coeff. & SE & Coeff. & SE \\
\hline Intercept & $-2.785 *$ & 0.062 & $-2.775 *$ & 0.062 & $-3.150 * *$ & 0.055 & $-3.129 * *$ & 0.055 \\
\hline $\operatorname{Ln}(t)$ & -0.018 & 0.018 & -0.026 & 0.018 & $0.126 * *$ & 0.016 & $0.118 * *$ & 0.016 \\
\hline Growth rate & $-0.867 * *$ & 0.013 & $-0.174 * *$ & 0.004 & $-0.325 * *$ & 0.006 & $-0.136 * *$ & 0.005 \\
\hline Growth rate squared & $1.157 * *$ & 0.014 & $0.277 * *$ & 0.004 & $0.259 * *$ & 0.005 & $0.222 * *$ & 0.004 \\
\hline $\operatorname{Ln}($ firm size $)$ & $-0.250 * *$ & 0.003 & $-0.255^{*} *$ & 0.003 & $-0.322 * *$ & 0.002 & $-0.320 * *$ & 0.002 \\
\hline \multicolumn{9}{|l|}{ Firm age (year) } \\
\hline 2 & & & & & $0.985 * *$ & 0.038 & $0.969 * *$ & 0.038 \\
\hline 3 & & & & & $0.831 * *$ & 0.033 & $0.819 * *$ & 0.033 \\
\hline 4 & $0.412 * *$ & 0.034 & $0.399 * *$ & 0.034 & $0.662 * *$ & 0.030 & $0.651 * *$ & 0.030 \\
\hline 5 & $0.367 * *$ & 0.030 & $0.357 * *$ & 0.031 & $0.586^{* *}$ & 0.027 & $0.576 * *$ & 0.027 \\
\hline 6 & $0.237 * *$ & 0.028 & $0.227 * *$ & 0.028 & $0.441 * *$ & 0.025 & $0.433 * *$ & 0.025 \\
\hline 7 & $0.172 * *$ & 0.026 & $0.162 * *$ & 0.026 & $0.355 * *$ & 0.023 & $0.348 * *$ & 0.023 \\
\hline 8 & $0.145 * *$ & 0.024 & $0.135 *$ & 0.024 & $0.297 * *$ & 0.021 & $0.290 * *$ & 0.021 \\
\hline 9 & $0.085 * *$ & 0.022 & $0.077^{*}$ & 0.023 & $0.226 * *$ & 0.020 & $0.219 * *$ & 0.020 \\
\hline $10-14$ & 0.013 & 0.018 & 0.007 & 0.018 & $0.117 * *$ & 0.016 & $0.112 * *$ & 0.016 \\
\hline $15-24$ & $-0.090 * *$ & 0.011 & $-0.092 * *$ & 0.011 & $0.054 * *$ & 0.009 & $0.052 * *$ & 0.009 \\
\hline \multicolumn{9}{|l|}{$\geq 25$ (reference cat.) } \\
\hline Urbanization & $0.108 * *$ & 0.004 & $0.110 * *$ & 0.004 & $0.146 * *$ & 0.003 & $0.146^{* *}$ & 0.003 \\
\hline Industry dummies & \multicolumn{2}{|c|}{ Included } & \multicolumn{2}{|c|}{ Included } & \multicolumn{2}{|c|}{ Included } & \multicolumn{2}{|c|}{ Included } \\
\hline Observations & \multicolumn{2}{|c|}{$5,798,399$} & \multicolumn{2}{|c|}{$5,774,323$} & \multicolumn{2}{|c|}{$9,180,025$} & \multicolumn{2}{|c|}{$9,203,240$} \\
\hline LR chi square & \multicolumn{2}{|c|}{$44,487.36^{* *}$} & \multicolumn{2}{|c|}{$45,168.27 * *$} & \multicolumn{2}{|c|}{$112,489.78 * *$} & \multicolumn{2}{|c|}{$112,364.22 * *$} \\
\hline
\end{tabular}

Dependent variable: exit due to firm death (value 1) versus continuation (value 0 ).

$* P<0.0001$;

$* P<0.001$.

The results provide support for our hypothesis given the significant negative linear and significant positive squared term for firm growth. This finding holds for each model specification in Table 5. Hence, the first step-a significant coefficient for age squared—-to validate a U-shaped relationship has been fulfilled (Haans et al., 2016). The second step involves the confidence intervals of the turning points. The inflection points at which the relationship between growth and exit becomes positive amount to growth rates of $0.37[95 \% \mathrm{CI}=(0.36 ; 0.39)], 0.31[95 \% \mathrm{CI}=$ $(0.29 ; 0.33)], 0.63[95 \% \mathrm{CI}=(0.61 ; 0.65)]$, and $0.31[95 \% \mathrm{CI}=(0.28 ; 0.33)]$ in Models $1,2,3$, and 4 in Table 5 , respectively. Hence, the inflection points lie well within the growth range. The third step involves the calculation of the steepness of the slope of the U-shape at the lower and upper part of the U-shape. The marginal effects as calculated below (Section 4.2) represent steep slopes at both ends of the U-shape. Hence, the three steps are validated.

Regarding the control variables, firm size has a negative relationship with the probability of exit in each model specification, which is in line with our expectations. As far as the enterprise's age is concerned, we see that firm age and exit due to firm death are negatively related. In other words, the exit rates are consistently the lowest among firms aged 15 years or more and highest for the youngest firms. The results for the industry dummies (not shown in the table for the sake of brevity but available upon request) reveal that exit rates are consistently lowest in the construction sector and highest in financial services, hotels and restaurants, wholesale, and chemical manufacturing sectors. We note that firms located in urban areas have significantly higher exit rates due to firm death than firms located in less urbanized areas.

\subsection{Marginal effects and predicted probabilities}

We provide two ways to enhance the interpretation of the results and to validate the presence of the U-shapes. First, marginal effects (at the means of the variables) are calculated and are displayed in Table 6. These numbers indicate 
Table 6. Marginal effects based on discrete-time proportional hazard regressions in Table 5

\begin{tabular}{|c|c|c|c|c|}
\hline \multirow[b]{3}{*}{ Value firm growth } & \multicolumn{2}{|l|}{ 3-year growth } & \multicolumn{2}{|l|}{ 1-year growth } \\
\hline & Annualized growth (1) & Logarithmic growth (2) & Annualized growth (3) & Logarithmic growth (4) \\
\hline & Marginal effect & Marginal effect & Marginal effect & Marginal effect \\
\hline-1.50 & & $-0.121 * *$ & & $-0.098 * *$ \\
\hline-1.25 & & $-0.088 * *$ & & $-0.074 * *$ \\
\hline-1.00 & & $-0.063 * *$ & & $-0.055 *$ \\
\hline-0.75 & & $-0.044 * *$ & & $-0.040 * *$ \\
\hline-0.50 & $-0.221 * *$ & $-0.030 *$ & $-0.050 * *$ & $-0.028 * *$ \\
\hline-0.25 & $-0.112 * *$ & $-0.019 * *$ & $-0.035 * *$ & $-0.018 * *$ \\
\hline 0.00 & $-0.052 * *$ & $-0.010 * *$ & $-0.023 * *$ & $-0.010 * *$ \\
\hline 0.25 & $-0.015 * *$ & $-0.002 * *$ & $-0.013 * *$ & $-0.002 * *$ \\
\hline 0.50 & $0.015 * *$ & $0.006^{* *}$ & $-0.004 * *$ & $0.006 * *$ \\
\hline 0.75 & $0.052 * *$ & $0.015 * *$ & $0.004 * *$ & $0.014 * *$ \\
\hline 1.00 & $0.112 * *$ & $0.025^{* *}$ & $0.013 * *$ & $0.023 * *$ \\
\hline 1.25 & $0.221 * *$ & $0.037 * *$ & $0.023 * *$ & $0.034 * *$ \\
\hline 1.50 & $0.421 * *$ & $0.053 * *$ & $0.034 * *$ & $0.047^{* *}$ \\
\hline
\end{tabular}

$* P<0.0001 ;$

$* P<0.001$.
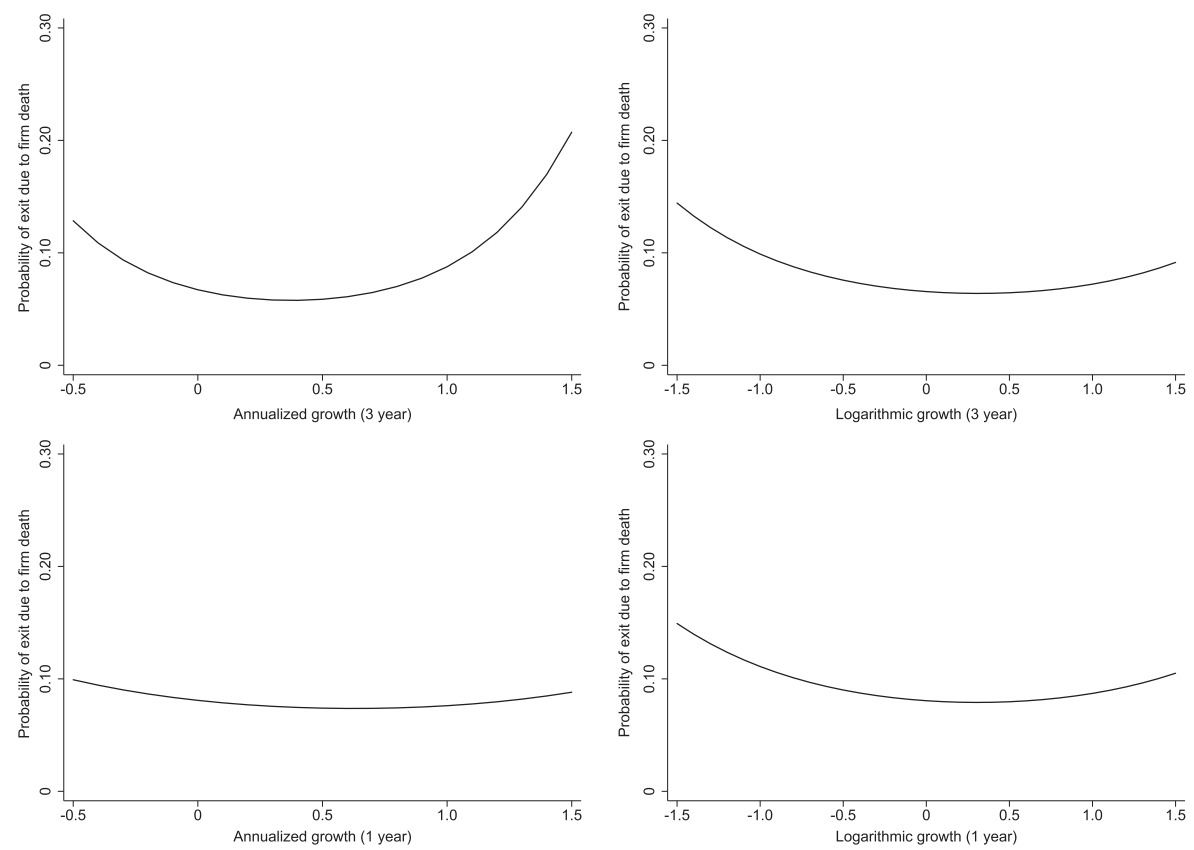

Figure 2. Predicted probability of exit due to firm death across the growth distribution: (A) 3-year annualized growth; (B) 3-year logarithmic growth; (C) 1-year annualized growth; (D) 1-year logarithmic growth.

the instantaneous rate of change in the probability of exit due to firm death for various values of firm growth. Again, Models 1 and 2 focus on the 3-year measures of annualized and logarithmic growth, and Models 3 and 4 show the results for the 1-year measures. The dispersion of the two growth measures is different in the sense that values below -0.50 for annualized firm growth are not very common in the dataset, which explains the different starting points for annualized and logarithmic growth in Table 6; all endpoints are at 1.50. Notice that the negative marginal effects 

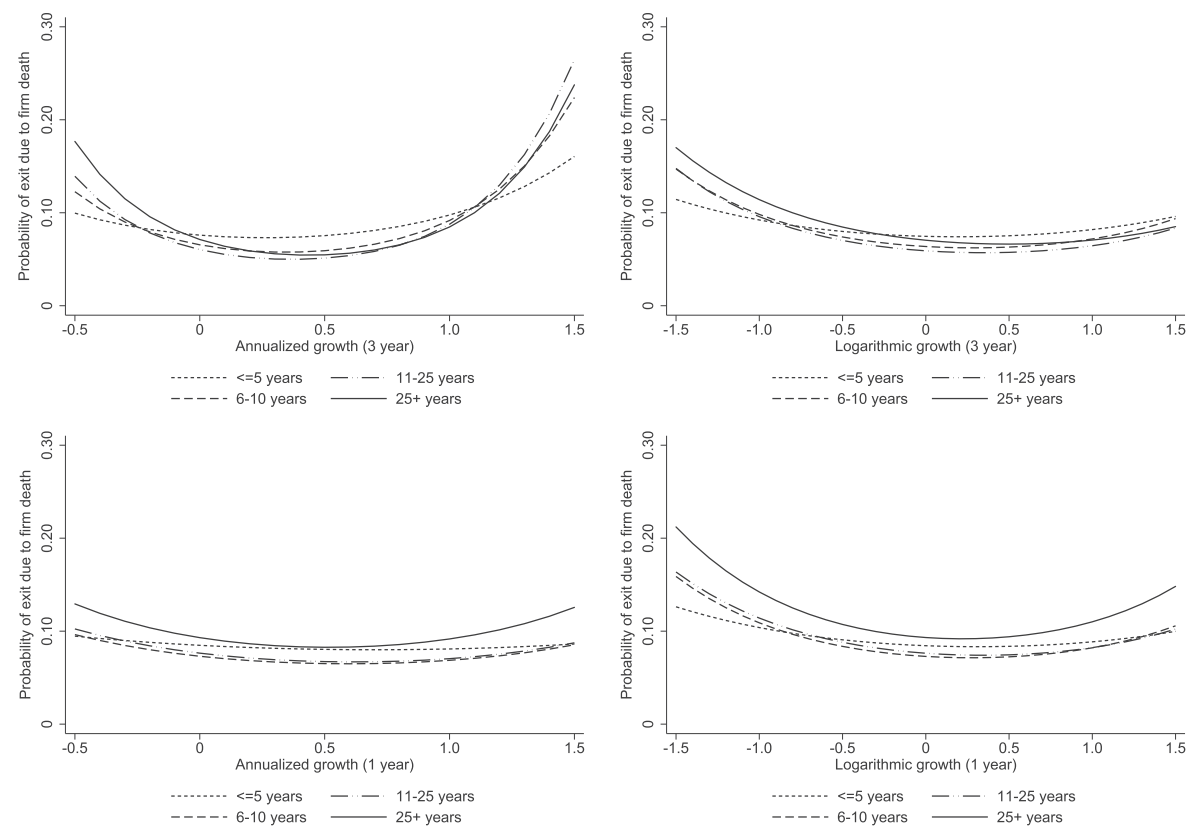

Figure 3. Predicted probability of exit due to firm death for various categories of firm age: (A) 3-year annualized growth; (B) 3-year logarithmic growth; (C) 1-year annualized growth; and (D) 1-year logarithmic growth.

for negative values of firm growth and the positive marginal effects for large positive values of firm growth are substantial given that the baseline probability of exit due to firm death is $6.88 \%$ (see Table 2).

Second, we calculate the predicted probability of exit due to firm death for various values of firm growth. The resulting plots are displayed in Figure 2. Graphs A (upper left) and B (upper right) focus on the 3-year measures of annualized (nonlogarithmic) and logarithmic growth, whereas Graphs C (lower left) and D (lower right) focus on the 1-year measures of both growth measures. The graphs in Figure 2 validate the presence of the U-shapes: they again show that the probability of exit decreases substantially for negative values of firm growth and that the probability of exit indeed tends to increase beyond the earlier calculated inflection points.

\subsection{Additional analyses and robustness checks}

\subsubsection{Context-specific inflection point of firm growth}

Figure 3 extends the analysis of Figure 2 and shows the results for various subgroups of firms based on their age: firms that have existed for up to 5 years, 6-10 years, 11-25 years, and more than 25 years. ${ }^{9}$ The steepness of the Ushape is roughly similar for the age groups, but there is one exception: the probability of exit varies more substantially across the growth distribution among the older firms (at least 6 years old) than among the youngest firms (up to 5 years).

Figure 4 distinguishes between firms based on the size at the start of the growth period: $<10$ employees, 10-49 employees, and 50-249 employees (firms with at least 250 employees are excluded from Figure 4 because of the low prevalence of this group). The U-shape seems most pronounced for the micro firms ( $<10$ employees). This is probably not surprising because micro firms need to grow in excess of a particular rate to decrease the probability of exit. Furthermore, the increase in the probability of exit at the higher end of the growth distribution seems absent for the larger firms (10-49 employees, 50-249 employees) on some occasions.

9 The graphs in Figures 3-6 are based on models with interaction terms between our growth measures and the various categories of firm size, age, and industry. The regression results are not displayed here but are available from the authors upon request. 

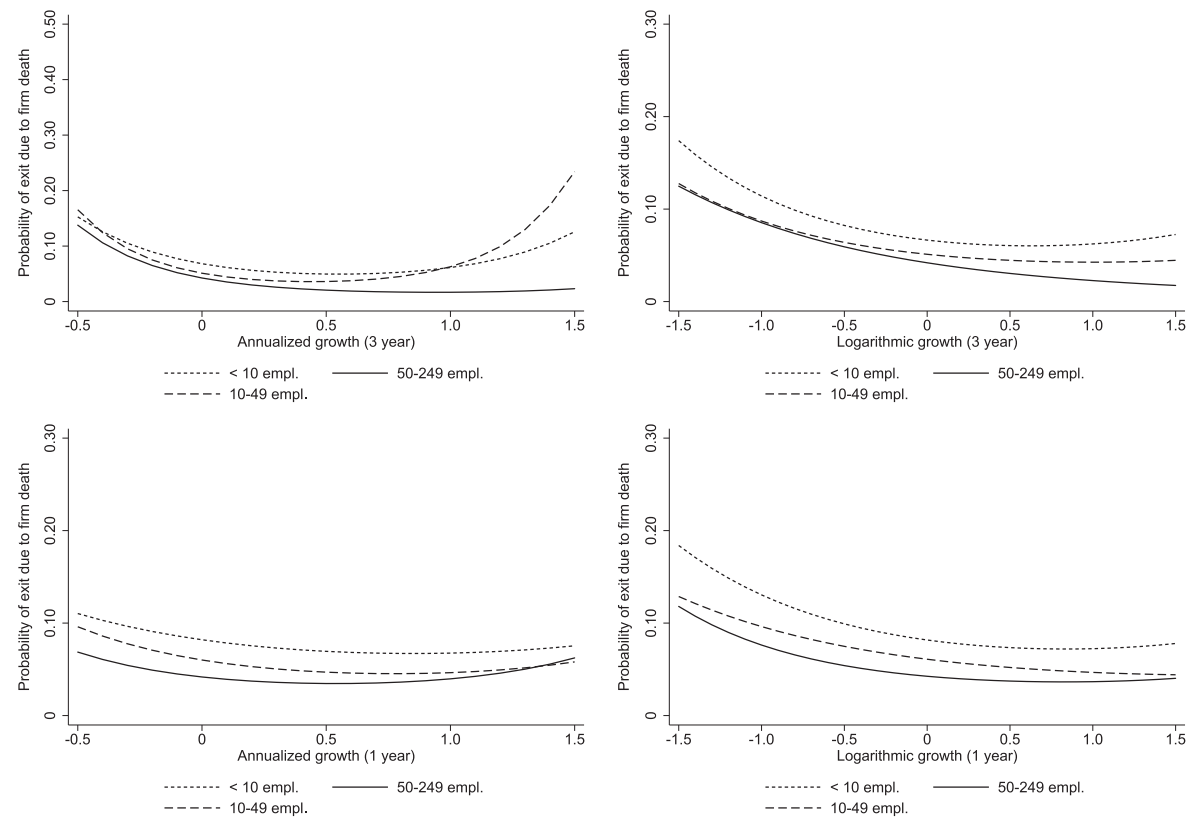

Figure 4. Predicted probability of exit due to firm death for various categories of firm size: (A) 3-year annualized growth; (B) 3-year logarithmic growth; (C) 1-year annualized growth; and (D) 1-year logarithmic growth.
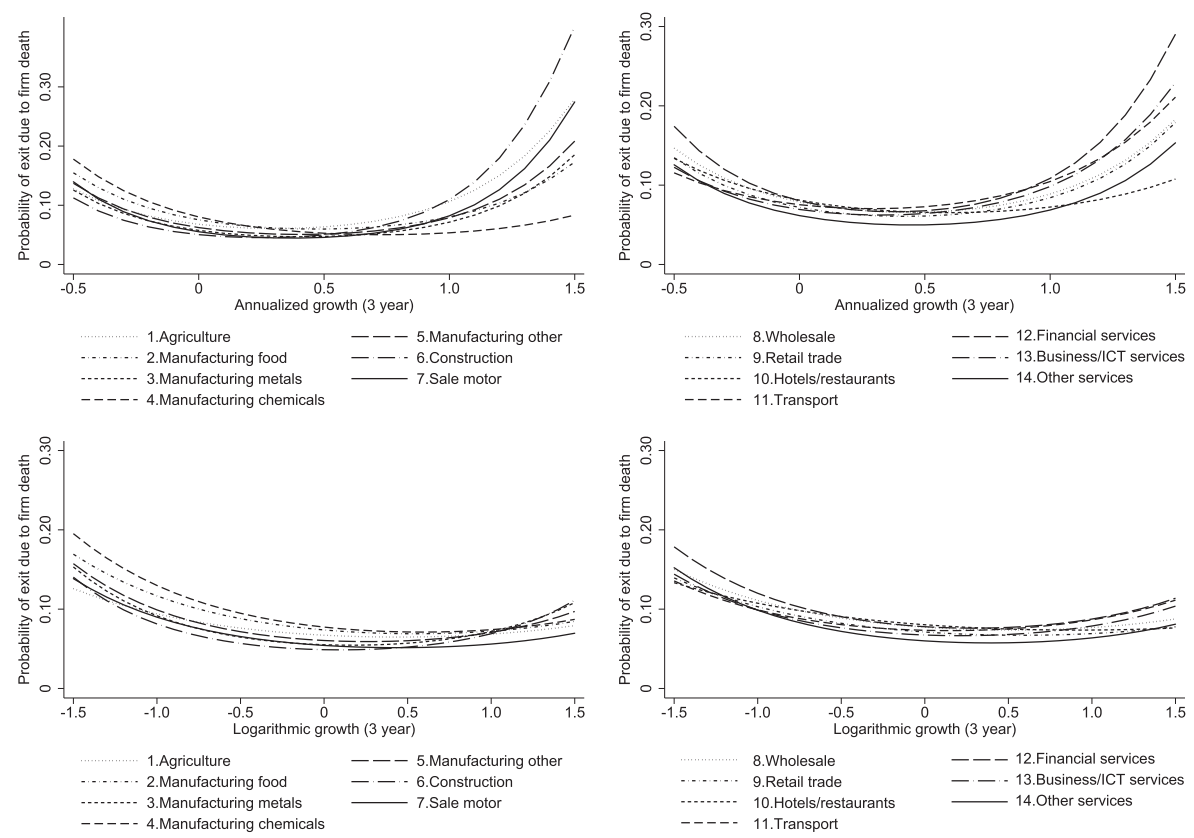

Figure 5. Predicted probability of exit due to firm death for firm growth for various sectors: (A) 3-year annualized growth sectors 1-7; (B) 3-year annualized growth sectors 8-14; (C) 3-year logarithmic growth sectors 1-7; and (D) 3-year logarithmic growth sectors 8-14.

Finally, Figures 5 and 6 visualize sector differences. A U-shaped relationship between growth and exit seems to hold for almost all sectors; the steepest U-shapes can be found in the manufacturing (other), financial services, and construction sectors. 

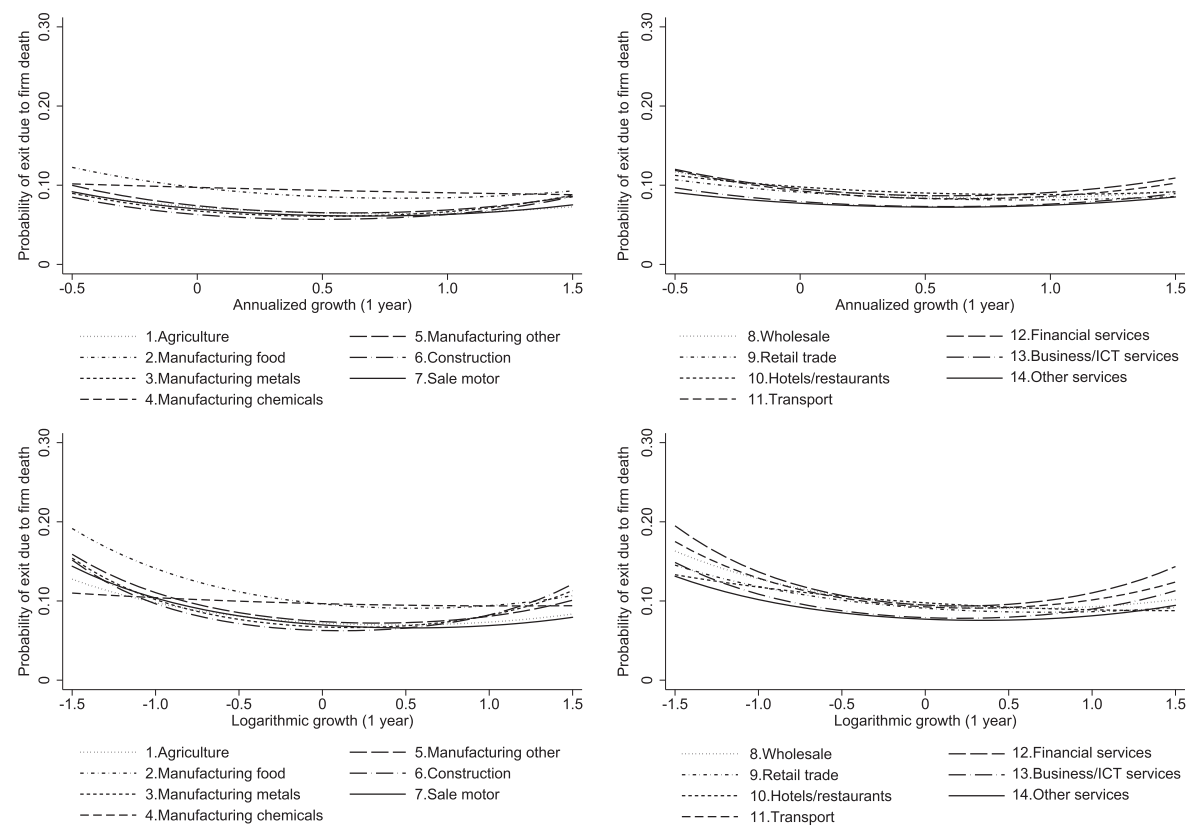

Figure 6. Predicted probability of exit due to firm death for firm growth for various sectors: (A) 1-year annualized growth sectors 1-7; (B) 1-year annualized growth sectors 8-14; (C) 1-year logarithmic growth sectors 1-7; and (D) 1-year logarithmic growth sectors 8-14.

\subsubsection{Positive growth}

We determine whether the relationship between growth and exit is different for firms with negative growth rates (declines) and for firms with positive growth rates (including zero growth). Interaction terms between the growth variables and an indicator function for firms with negative growth rates reveal that this is the case (results not shown). We show the regressions for the observations with positive growth (including zero) in Table 7. A U-shaped relationship between firm growth and exit due to firm death is found in three out of four model specifications. The turning points of the $\mathrm{U}$-shapes are at $0.17[95 \% \mathrm{CI}=(0.11 ; 0.22)]$ for the 3 -year logarithmic growth rate, $0.63[95 \%$ $\mathrm{CI}=(0.60 ; 0.67)]$ for the 1 -year nonlogarithmic growth rate, and $0.44[95 \% \mathrm{CI}=(0.42 ; 0.46)]$ for the 1-year logarithmic growth rate.

\subsubsection{Categorical growth variables}

It may be possible that the linear and quadratic terms oversee relevant information about the nonlinear relationship between growth and exit due to firm death. This leads us to perform regressions including categorical variables for firm growth. A second reason for performing these regressions is that there may be a concern for multicollinearity because of the simultaneous inclusion of the linear and quadratic growth terms.

The results of analyses where the linear and quadratic terms of firm growth have been replaced with dummy variables indicating intervals of the growth distribution (in 10 percentage points, or 50 percentage points for the extremes of the growth distributions) are shown in Table 8 . The category $(-0.10 ; 0.00)$ is taken as the reference category in each regression.

The results in Table 8 can be summarized as follows. First, we find relatively large positive and significant coefficients belonging to categories indicating a substantial decline in the number of employees. Second, a decreasing pattern of coefficients can be observed in the "decline range." Third, the largest negative coefficients can generally be observed for the growth categories $(0 ; 0.1),(0.1 ; 0.2)$, and $(0.2 ; 0.3)$. Hence, firms that grow between 0 (excluding 0 ) and $30 \%$ on a 1 -year or 3 -year basis generally have the lowest probabilities of exit, and their probability of exit is significantly smaller than firms that experience stagnant growth or that decline only marginally [category $(-0.10 ; 0.00)]$. Fourth, we see relative high probabilities of exit for fast-growing firms, although the magnitude and significance of the dummy variables differ across the model specifications. For example, the coefficient belonging to the $(0.6 ; 0.7)$ category has a significant positive coefficient in 3 out of 4 model 
Table 7. Regression results discrete-time logistic proportional hazard models, non-negative sample

\begin{tabular}{|c|c|c|c|c|c|c|c|c|}
\hline & \multicolumn{4}{|l|}{ 3-year growth } & \multicolumn{4}{|l|}{ 1-year growth } \\
\hline & \multicolumn{2}{|c|}{ Annualized growth (1) } & \multicolumn{2}{|c|}{ Logarithmic growth (2) } & \multicolumn{2}{|c|}{ Annualized growth (3) } & \multicolumn{2}{|c|}{ Logarithmic growth (4) } \\
\hline & Coeff. & SE & Coeff. & SE & Coeff. & SE & Coeff. & SE \\
\hline Intercept & $-2.751 * *$ & 0.073 & $-2.758 * *$ & 0.073 & $-3.235 * *$ & 0.059 & $-3.233 * *$ & 0.059 \\
\hline $\operatorname{Ln}(t)$ & -0.031 & 0.021 & -0.028 & 0.021 & $0.146 * *$ & 0.017 & $0.145 * *$ & 0.017 \\
\hline Growth rate & $0.339 * *$ & 0.027 & $-0.079 * *$ & 0.017 & $-0.215^{* *}$ & 0.015 & $-0.328 * *$ & 0.017 \\
\hline Growth rate squared & $0.184 * *$ & 0.026 & $0.238 * *$ & 0.014 & $0.169 * *$ & 0.010 & $0.371 * *$ & 0.015 \\
\hline $\operatorname{Ln}($ firm size $)$ & $-0.296^{* *}$ & 0.004 & $-0.293 *$ & 0.004 & $-0.316^{* *}$ & 0.002 & $-0.313 * *$ & 0.002 \\
\hline \multicolumn{9}{|l|}{ Firm age (years) } \\
\hline 2 & & & & & $1.046 * *$ & 0.040 & $1.044 * *$ & 0.040 \\
\hline 3 & & & & & $0.888 * *$ & 0.036 & $0.886 * *$ & 0.036 \\
\hline 4 & $0.419 * *$ & 0.040 & $0.423 * *$ & 0.040 & $0.711^{* *}$ & 0.032 & $0.709 * *$ & 0.032 \\
\hline 5 & $0.377^{* *}$ & 0.036 & $0.380 * *$ & 0.036 & $0.623 *$ & 0.029 & $0.622 * *$ & 0.029 \\
\hline 6 & $0.219 * *$ & 0.033 & $0.221 * *$ & 0.033 & $0.470 * *$ & 0.027 & $0.470 * *$ & 0.027 \\
\hline 7 & $0.144 * *$ & 0.030 & $0.146 * *$ & 0.030 & $0.374 * *$ & 0.025 & $0.374 * *$ & 0.025 \\
\hline 8 & $0.120 * *$ & 0.028 & $0.122 * *$ & 0.028 & $0.319 * *$ & 0.023 & $0.318 * *$ & 0.023 \\
\hline 9 & 0.059 & 0.026 & 0.060 & 0.026 & $0.242 * *$ & 0.021 & $0.242 * *$ & 0.021 \\
\hline $10-14$ & -0.009 & 0.021 & -0.007 & 0.021 & $0.128 * *$ & 0.017 & $0.128 * *$ & 0.017 \\
\hline $15-24$ & $-0.104 * *$ & 0.013 & $-0.104 * *$ & 0.013 & $0.070 * *$ & 0.010 & $0.069 * *$ & 0.010 \\
\hline \multicolumn{9}{|l|}{$\geq 25$ (reference cat.) } \\
\hline Urbanization & $0.118 * *$ & 0.005 & $0.117 * *$ & 0.005 & $0.146^{* *}$ & 0.003 & $0.146 * *$ & 0.003 \\
\hline Industry dummies & \multicolumn{2}{|c|}{ Included } & \multicolumn{2}{|c|}{ Included } & \multicolumn{2}{|c|}{ Included } & \multicolumn{2}{|c|}{ Included } \\
\hline Observations & \multicolumn{2}{|c|}{$4,743,625$} & \multicolumn{2}{|c|}{$4,730,625$} & \multicolumn{2}{|c|}{$8,264,086$} & \multicolumn{2}{|c|}{$8,295,490$} \\
\hline LR chi square & \multicolumn{2}{|c|}{$29,430.93 * *$} & \multicolumn{2}{|c|}{$29,578.67 * *$} & \multicolumn{2}{|c|}{$92,580.90 * *$} & \multicolumn{2}{|c|}{$92,650.04 * *$} \\
\hline
\end{tabular}

Dependent variable: exit due to firm death (value 1) versus continuation (value 0 ).

$* P<0.0001$;

$* P<0.001$.

specifications, and additional Wald tests reveal that the coefficient of the $(0.6 ; 0.7)$ category is significantly larger than the coefficient of the $(0 ; 0.1)$ category in each model specification. We thus find evidence that rapid growth could be harmful.

\subsubsection{Lagged firm size}

We believe it is appropriate to include firm size of the previous period in the regressions-this is also in line with studies such as Coad et al. (2013, 2016a)—to properly distinguish between a growth effect and a final size effect. Table 9 shows the results when firm size at the start of the growth period is included as a control variable. Generally, we find qualitatively similar results for the control variables as in Table 5, but the growth thresholds of the U-shapes in Table 9 occur somewhat later than in Table 5.

\subsubsection{Nonorganic growth}

Finally, we know whether a firm's growth was organic (no merging, acquisition or restructuring took place during the firm's growth path) or nonorganic. Hazard models that also include firms that experienced nonorganic growth are presented in Table 10. The fact that nonorganic growth was achieved has been added as a control variable. We note that firms that experience nonorganic growth experience lower exit rates than firms that achieved growth organically. This finding is related to the results in Spearot (2012) in that higher productivity firms are more likely to choose acquisitions than new investments, where investments involve purchasing a new plant and acquisitions involve purchasing a plant from a selling firm. The estimates of the coefficients of the growth variables and control variables remain unaffected by the inclusion of the nonorganic growth variable. 
Table 8. Regression results discrete-time logistic proportional hazard models with growth categories included

\begin{tabular}{|c|c|c|c|c|c|c|c|c|}
\hline \multirow[b]{3}{*}{ Category } & \multicolumn{4}{|l|}{ 3-year growth } & \multicolumn{4}{|l|}{ 1-year growth } \\
\hline & \multicolumn{2}{|c|}{ Annualized growth (1) } & \multicolumn{2}{|c|}{ Logarithmic growth (2) } & \multicolumn{2}{|c|}{ Annualized growth (3) } & \multicolumn{2}{|c|}{ Logarithmic growth (4) } \\
\hline & Coeff. & SE & Coeff. & SE & Coeff. & SE & Coeff. & SE \\
\hline$(-2.00 ; 1.50)$ & & & $0.943 * *$ & 0.020 & & & $0.842 * *$ & 0.023 \\
\hline$(-1.50 ;-1.00)$ & & & $0.700 * *$ & 0.011 & & & $0.559 * *$ & 0.013 \\
\hline$(-1.00 ;-0.50)$ & $1.201 * *$ & 0.024 & $0.285 * *$ & 0.006 & $0.322 * *$ & 0.006 & $0.204 * *$ & 0.006 \\
\hline$(-0.50 ;-0.40)$ & $0.957 * *$ & 0.021 & $0.120 * *$ & 0.008 & $0.137 * *$ & 0.019 & 0.002 & 0.008 \\
\hline$(-0.40 ;-0.30)$ & $0.709 * *$ & 0.011 & $0.094 *$ & 0.026 & 0.005 & 0.008 & 0.044 & 0.027 \\
\hline$(-0.30 ;-0.20)$ & $0.300 * *$ & 0.007 & $0.040 *$ & 0.011 & $-0.107 * *$ & 0.010 & $-0.116 * *$ & 0.011 \\
\hline$(-0.20 ;-0.10)$ & $0.130 * *$ & 0.007 & -0.055 & 0.017 & $-0.205 * *$ & 0.015 & $-0.213 * *$ & 0.016 \\
\hline$(-0.10 ; 0.00)$ & Ref. & & Ref. & & Ref. & & Ref. & \\
\hline$(0.00 ; 0.10)$ & $-0.174 * *$ & 0.013 & 0.024 & 0.030 & $-0.438 * *$ & 0.030 & $-0.386^{* *}$ & 0.027 \\
\hline$(0.10 ; 0.20)$ & $-0.144 * *$ & 0.008 & $-0.174 * *$ & 0.018 & $-0.298 * *$ & 0.019 & $-0.323 *$ & 0.016 \\
\hline$(0.20 ; 0.30)$ & $0.125 * *$ & 0.008 & $-0.218 * *$ & 0.012 & $-0.318 * *$ & 0.015 & $-0.315^{* *}$ & 0.012 \\
\hline$(0.30 ; 0.40)$ & 0.068 & 0.021 & $-0.096^{*}$ & 0.028 & $-0.314 * *$ & 0.014 & $-0.181 * *$ & 0.029 \\
\hline$(0.40 ; 0.50)$ & $0.193 * *$ & 0.017 & $-0.108 * *$ & 0.010 & $-0.222 * *$ & 0.010 & $-0.215 *$ & 0.010 \\
\hline$(0.50 ; 0.60)$ & $0.188 * *$ & 0.027 & $-0.134 * *$ & 0.020 & 0.006 & 0.063 & $-0.162 * *$ & 0.021 \\
\hline$(0.60 ; 0.70)$ & $0.495 * *$ & 0.052 & $0.134 * *$ & 0.008 & $-0.174 * *$ & 0.023 & $0.120 * *$ & 0.008 \\
\hline$(0.70 ; 0.80)$ & $0.353 * *$ & 0.039 & 0.137 & 0.061 & -0.090 & 0.043 & 0.099 & 0.070 \\
\hline$(0.80 ; 0.90)$ & $0.317^{* *}$ & 0.052 & 0.065 & 0.036 & -0.029 & 0.052 & 0.076 & 0.043 \\
\hline$(0.90 ; 1.00)$ & $0.514 * *$ & 0.048 & 0.072 & 0.026 & $0.122 * *$ & 0.008 & -0.030 & 0.032 \\
\hline$(1.00 ; 1.50)$ & $0.572 * *$ & 0.042 & $0.205 * *$ & 0.014 & 0.010 & 0.026 & $0.067^{*}$ & 0.017 \\
\hline$(1.50 ; 2.00)$ & $0.622 * *$ & 0.071 & $0.373 * *$ & 0.026 & 0.025 & 0.020 & $0.291 * *$ & 0.032 \\
\hline
\end{tabular}

Dependent variable: exit due to firm death (value 1) versus continuation (value 0 ).

$* P<0.0001$;

$* P<0.001$. The same set of control variables is included as in Table 5. These results are omitted from the table for brevity but are available from the authors upon request.

\subsubsection{Selection model}

In our regressions with the 3-year growth measures, firms are excluded when they do not continue their activities for three consecutive years. There could be a sample selection issue here because firms included in the regressions are a subset of firms that originally entered the market. The sample selection issue is expected to be small in our case partly because we have a census-based dataset rather than a survey-based dataset and because we always keep track of firms when they exit from the market place. In addition, we present our results for the 1-year growth measures throughout the manuscript. Nevertheless, we show the estimates of a Heckman-type correction model consisting of a selection model explaining 3-year growth and an outcome model explaining exit due to firm death in Table 11. The estimated correlations between the selection equation and the outcome equation are significantly different from zero. This is an indication that we should probably attach some more importance to the results containing 1-year growth measures than 3 -year growth measures in Table 5. Note that the results of the control variables in Table 11 in terms of their significance remain unaffected, except for the urbanization variable. The results in Table 11 again demonstrate the presence of a U-shaped relationship between firm growth and exit due to firm death.

\section{Discussion and conclusion}

The present paper echoes the current interest in HGFs (Coad et al., 2014a) and investigates how the probability of exit varies across the growth distribution of Dutch firms in the period of 1999-2012. The manuscript provides empirical insight into the question of whether a period of (high) employment growth can also be followed by exit due to firm death. Due to their contribution to wealth and job creation, HGFs are considered an important political objective by policy makers (European Commission, 2010; OECD, 2010). Growing quickly may, however, also be 
Table 9. Regression results discrete-time logistic proportional hazard models with lagged firm size

\begin{tabular}{|c|c|c|c|c|c|c|c|c|}
\hline & \multicolumn{4}{|l|}{ 3-year growth } & \multicolumn{4}{|l|}{ 1-year growth } \\
\hline & \multicolumn{2}{|c|}{ Annualized growth (1) } & \multicolumn{2}{|c|}{ Logarithmic growth (2) } & \multicolumn{2}{|c|}{ Annualized growth (3) } & \multicolumn{2}{|c|}{ Logarithmic growth (4) } \\
\hline & Coeff. & SE & Coeff. & SE & Coeff. & SE & Coeff. & SE \\
\hline Intercept & $-2.776 * *$ & 0.062 & $-2.775 *$ & 0.062 & $-3.145 * *$ & 0.055 & $-3.129 * *$ & 0.055 \\
\hline $\operatorname{Ln}(t)$ & -0.024 & 0.018 & -0.026 & 0.018 & $0.121 * *$ & 0.016 & $0.118 * *$ & 0.016 \\
\hline Growth rate & $-1.648 * *$ & 0.013 & $-0.429 * *$ & 0.004 & $-0.713 * *$ & 0.006 & $-0.456 * *$ & 0.005 \\
\hline Growth rate squared & $1.388 * *$ & 0.014 & $0.277 * *$ & 0.004 & $0.387 * *$ & 0.005 & $0.222 * *$ & 0.004 \\
\hline $\operatorname{Ln}$ (firm size) lagged & $-0.239 * *$ & 0.003 & $-0.255^{*} *$ & 0.003 & $-0.310 * *$ & 0.002 & $-0.320 * *$ & 0.002 \\
\hline \multicolumn{9}{|l|}{ Firm age (years) } \\
\hline 2 & & & & & $0.979 * *$ & 0.038 & $0.969 * *$ & 0.038 \\
\hline 3 & & & & & $0.825 * *$ & 0.033 & $0.819 * *$ & 0.033 \\
\hline 4 & $0.405 *$ & 0.034 & $0.399 * *$ & 0.034 & $0.657^{* *}$ & 0.030 & $0.651 * *$ & 0.030 \\
\hline 5 & $0.361 * *$ & 0.030 & $0.357 * *$ & 0.031 & $0.582 * *$ & 0.027 & $0.576 * *$ & 0.027 \\
\hline 6 & $0.232 * *$ & 0.028 & $0.227 * *$ & 0.028 & $0.437 * *$ & 0.025 & $0.433 * *$ & 0.025 \\
\hline 7 & $0.168 * *$ & 0.026 & $0.162 * *$ & 0.026 & $0.352 * *$ & 0.023 & $0.348 * *$ & 0.023 \\
\hline 8 & $0.141 * *$ & 0.024 & $0.135 *$ & 0.024 & $0.294 * *$ & 0.021 & $0.290 * *$ & 0.021 \\
\hline 9 & $0.082 *$ & 0.022 & $0.077^{*}$ & 0.023 & $0.223 * *$ & 0.020 & $0.219 * *$ & 0.020 \\
\hline $10-14$ & 0.011 & 0.018 & 0.007 & 0.018 & $0.116 * *$ & 0.016 & $0.112 * *$ & 0.016 \\
\hline $15-24$ & $-0.090 * *$ & 0.011 & $-0.092 * *$ & 0.011 & $0.054 *$ & 0.009 & $0.052 * *$ & 0.009 \\
\hline \multicolumn{9}{|l|}{$\geq 25$ (reference cat.) } \\
\hline Urbanization & $0.108 * *$ & 0.004 & $0.110 * *$ & 0.004 & $0.146 * *$ & 0.003 & $0.146 * *$ & 0.003 \\
\hline Industry dummies & \multicolumn{2}{|c|}{ Included } & \multicolumn{2}{|c|}{ Included } & \multicolumn{2}{|c|}{ Included } & \multicolumn{2}{|c|}{ Included } \\
\hline Observations & \multicolumn{2}{|c|}{$5,798,399$} & \multicolumn{2}{|c|}{$5,774,323$} & \multicolumn{2}{|c|}{$9,180,025$} & \multicolumn{2}{|c|}{$9,203,240$} \\
\hline LR chi square & \multicolumn{2}{|c|}{$43,888.19 * *$} & \multicolumn{2}{|c|}{$45,168.27 * *$} & \multicolumn{2}{|c|}{$111,266.54^{* * *}$} & \multicolumn{2}{|c|}{$112,364.22 * *$} \\
\hline
\end{tabular}

Dependent variable: exit due to firm death (value 1) versus continuation (value 0 ).

** $P<0.0001$;

$* P<0.001$.

disadvantageous in the sense that firms may have a deficit of the "right" resources, managerial capabilities, and organizational structure to respond immediately to high employment growth. This may put the firm at risk of exiting due to firm death. Hence, while firm growth is generally considered beneficial for a firm, there may exist an inflection point of firm growth after which growth leads to an undesired outcome (Pierce and Aguinis, 2013), that is, exit due to firm death.

Adopting theoretical lenses from both the industrial organization literature and organization theory and based on the additive/cost arguments, as suggested by Haans et al. (2016), we developed a hypothesis about the U-shaped relationship between organic employment growth and the probability of exit due to firm death. Using data from the Dutch Business Register from Statistics Netherlands for the period of 1999-2012, we performed a range of discretetime logistic proportional hazard regressions with exit due to firm death as the dependent variable. Our empirical findings suggest the following. A U-shaped relationship between organic employment growth and exit due to firm death is validated for all our growth measures. We perform a range of robustness checks, and apart from a few exceptions-we find that our main result is robust to an analysis of the positive growth sample, the inclusion of lagged firm size, the analysis of organic and nonorganic growth, and sample selection correction.

Together with an additional analysis including firm growth categories, we arrive at the following three intriguing insights. First, the first part of the U-shape seems driven by enterprises that face employment contraction. More generally, the shape and steepness of the U-shape depend on the growth measure and model specification under investigation, where the differences in exit probabilities between firms experiencing positive growth are smaller than the differences among firms experiencing contraction. Second, we find that firms experiencing low growth have the lowest probability of exit, and their probability of exit is lower than that of firms experiencing zero growth; this result was already established on the basis of our descriptive analysis and is validated in our set of multivariate regressions. Third, we find some evidence that experiencing growth beyond some inflection point is detrimental for the 
Table 10. Regression results discrete-time logistic proportional hazard models including nonorganic growth

\begin{tabular}{|c|c|c|c|c|c|c|c|c|}
\hline & \multicolumn{4}{|l|}{ 3-year growth } & \multicolumn{4}{|c|}{ 1-year growth } \\
\hline & \multicolumn{2}{|c|}{ Annualized growth (1) } & \multicolumn{2}{|c|}{ Logarithmic growth (2) } & \multicolumn{2}{|c|}{ Annualized growth (3) } & \multicolumn{2}{|c|}{ Logarithmic growth (4) } \\
\hline & Coeff. & SE & Coeff. & SE & Coeff. & SE & Coeff. & SE \\
\hline Intercept & $-2.765 *$ & 0.060 & $-2.760 * *$ & 0.061 & $-3.142 * *$ & 0.054 & $-3.121 * *$ & 0.054 \\
\hline $\operatorname{Ln}(t)$ & -0.023 & 0.017 & -0.031 & 0.017 & $0.124 * *$ & 0.015 & $0.115 * *$ & 0.015 \\
\hline Nonorganic growth & $-0.851 *$ & 0.010 & $-0.891 * *$ & 0.010 & $-0.988 * *$ & 0.008 & $-1.012 * *$ & 0.008 \\
\hline Growth rate & $-0.947 * *$ & 0.013 & $-0.194 * *$ & 0.004 & $-0.364 * *$ & 0.006 & $-0.156 * *$ & 0.005 \\
\hline Growth rate squared & $1.162 * *$ & 0.013 & $0.276 * *$ & 0.004 & $0.283^{* *}$ & 0.005 & $0.232 * *$ & 0.004 \\
\hline $\operatorname{Ln}($ firm size $)$ & $-0.251 *$ & 0.003 & $-0.255^{* *}$ & 0.003 & $-0.320 *$ & 0.002 & $-0.317^{* *}$ & 0.002 \\
\hline \multicolumn{9}{|l|}{ Firm age (years) } \\
\hline 2 & & & & & $0.975^{* *}$ & 0.037 & $0.958 * *$ & 0.037 \\
\hline 3 & & & & & $0.823 * *$ & 0.033 & $0.811^{* *}$ & 0.033 \\
\hline 4 & $0.405^{* *}$ & 0.033 & $0.394 * *$ & 0.033 & $0.658 * *$ & 0.029 & $0.647 * *$ & 0.029 \\
\hline 5 & $0.358 * *$ & 0.030 & $0.350 * *$ & 0.030 & $0.582 * *$ & 0.027 & $0.571^{* *}$ & 0.027 \\
\hline 6 & $0.231 * *$ & 0.027 & $0.223 * *$ & 0.028 & $0.438 * *$ & 0.024 & $0.430 * *$ & 0.024 \\
\hline 7 & $0.169 * *$ & 0.025 & $0.161 * *$ & 0.025 & $0.355 * *$ & 0.022 & $0.347^{* *}$ & 0.022 \\
\hline 8 & $0.145^{* *}$ & 0.024 & $0.137 * *$ & 0.024 & $0.299 * *$ & 0.021 & $0.291 * *$ & 0.021 \\
\hline 9 & $0.089 * *$ & 0.022 & $0.081 *$ & 0.022 & $0.231 * *$ & 0.020 & $0.223 * *$ & 0.020 \\
\hline $10-14$ & 0.018 & 0.017 & 0.012 & 0.017 & $0.123^{* *}$ & 0.015 & $0.118 * *$ & 0.015 \\
\hline $15-24$ & $-0.083 * *$ & 0.011 & $-0.085^{* *}$ & 0.011 & $0.056^{* *}$ & 0.009 & $0.054 * *$ & 0.009 \\
\hline \multicolumn{9}{|l|}{$\geq 25$ (reference cat.) } \\
\hline Urbanization & $0.109 * *$ & 0.004 & $0.111^{* *}$ & 0.004 & $0.146 * *$ & 0.003 & $0.146 * *$ & 0.003 \\
\hline Industry dummies & \multicolumn{2}{|c|}{ Included } & \multicolumn{2}{|c|}{ Included } & \multicolumn{2}{|c|}{ Included } & \multicolumn{2}{|c|}{ Included } \\
\hline Observations & \multicolumn{2}{|c|}{$6,311,112$} & \multicolumn{2}{|c|}{$6,277,178$} & \multicolumn{2}{|c|}{$9,860,011$} & \multicolumn{2}{|c|}{$9,889,900$} \\
\hline LR chi square & \multicolumn{2}{|c|}{$68,657.57 * *$} & \multicolumn{2}{|c|}{$69,065.89 * *$} & \multicolumn{2}{|c|}{$158,438.30 * *$} & \multicolumn{2}{|c|}{$158,915.21 * *$} \\
\hline
\end{tabular}

Dependent variable: exit due to firm death (value 1) versus continuation (value 0 ).

$* P<0.0001$;

$* P<0.001$.

performance of the firm given the significantly higher probabilities of exit for subsets of HGFs compared with the firms that experience less rapid growth. In some specifications, we do not find much variety in the exit probability for certain ranges of positive firm growth, which could be understood in the context of Gibrat's law (see also our Section 2).

Our rich dataset allows us to explore the heterogeneity of the relationship between firm growth and exit in a detailed manner. We extracted some particular subgroups of firms-the micro firms with 10 employees at most, firms of at least 5 years old, and firms in the manufacturing, financial services, and construction sectors-for which the probability of exit increases after a certain inflection point of firm growth. Further research should reveal whether there is indeed a "curse of fast growth" (Hölzl, 2014: 200) for more refined categories of firms or for combinations of age, size, and sector.

Overall, heterogeneity exists in the relationship between firm growth and firm exit. Future samples may want to focus more on the industry aspect and to disentangle the different forms of competition that the firm faces in its environment, such as the difference between labor-intensive versus knowledge-intensive forms of competition. The context-specific inflection point (Pierce and Aguinis, 2013) and the use of various growth measures may explain the mixed results in existing studies on the relationship between growth and survival. In sum, the present study provides a more complete picture of the growth-exit relationship in the context of firm size, firm age and industry, while exploring the entire growth distribution ranging from large decline to substantial positive growth.

The present study comes with (data) limitations that future research might take into account to dig deeper into the relationship between (high) firm growth and exit/survival. First, we use employment growth as our growth indicator. Although we defended our choice in the paper, we acknowledge that using different growth measures, for example, in terms of sales or assets, may lead to different conclusions (Delmar and Wiklund, 2008; Delmar et al., 2013). Therefore, future research might consider using different growth indicators than the one used in the present 
Table 11. Regression results discrete-time logistic proportional hazard models, sample selection

\begin{tabular}{|c|c|c|c|c|}
\hline & \multicolumn{4}{|l|}{3 -year growth } \\
\hline & \multicolumn{2}{|c|}{ Annualized growth (1) } & \multicolumn{2}{|c|}{ Logarithmic growth (2) } \\
\hline & Coeff. & SE & Coeff. & SE \\
\hline Intercept & $-1.986 * *$ & 0.024 & $-1.983 * *$ & 0.025 \\
\hline $\operatorname{Ln}(t)$ & -0.009 & 0.007 & -0.012 & 0.007 \\
\hline Growth rate & $-0.354 * *$ & 0.005 & $-0.073 * *$ & 0.002 \\
\hline Growth rate squared & $0.488 * *$ & 0.006 & $0.114 * *$ & 0.002 \\
\hline $\operatorname{Ln}($ firm size $)$ & $-0.051 *$ & 0.001 & $-0.054 * *$ & 0.001 \\
\hline \multicolumn{5}{|l|}{ Firm age (years) } \\
\hline \multicolumn{5}{|l|}{2} \\
\hline \multicolumn{5}{|l|}{3} \\
\hline 4 & $0.162 * *$ & 0.013 & $0.157^{* *}$ & 0.013 \\
\hline 5 & $0.143^{* *}$ & 0.012 & $0.140 * *$ & 0.012 \\
\hline 6 & $0.091 * *$ & 0.011 & $0.088 * *$ & 0.011 \\
\hline 7 & $0.066 * *$ & 0.010 & $0.062 * *$ & 0.010 \\
\hline 8 & $0.056 * *$ & 0.010 & $0.052 * *$ & 0.010 \\
\hline 9 & $0.032 *$ & 0.009 & 0.029 & 0.009 \\
\hline $10-14$ & 0.004 & 0.007 & 0.002 & 0.007 \\
\hline $15-24$ & $-0.036^{* *}$ & 0.004 & $-0.037 * *$ & 0.004 \\
\hline \multicolumn{5}{|l|}{$\geq 25$ (reference cat.) } \\
\hline Urbanization & -0.004 & 0.002 & -0.003 & 0.002 \\
\hline Industry dummies & \multicolumn{2}{|c|}{ Included } & \multicolumn{2}{|c|}{ Included } \\
\hline Observations & \multicolumn{2}{|c|}{$5,798,399$} & \multicolumn{2}{|c|}{$5,774,323$} \\
\hline Wald chi square & \multicolumn{2}{|c|}{$28,665.44 * *$} & \multicolumn{2}{|c|}{$28,586.17 * *$} \\
\hline
\end{tabular}

Dependent variable in outcome equation: exit due to firm death (value 1) versus continuation (value 0 ).

$* P<0.0001 ;$

${ }^{*} P<0.001$. The results for the selection equation are omitted here for the sake of brevity.

paper to examine the relationship between growth and exit/survival. Second, the current study includes a small set of control variables due to data limitations. Future studies may want to take into account variables that measure the resources or capabilities of a firm to better justify the arguments based on Penrose's theory of the growth of the firm. Third, the current data do not allow for the identification of policy-induced growth. This is regrettable because results based on this subsample can have relevant policy implications. Fourth, although firms that grow organically in employment are the primary interest of policy makers due to their contribution to job creation, this cannot completely reflect the aggregate employment gains at the market level. Jobs that are created by some firms can be the result of business stealing, which results in job losses at their competitor firms. Future research could control for such information at the market or aggregated level.

To conclude, this paper provides new insight into the relationship between growth and exit by allowing for a nonlinear relationship between growth and exit. Importantly, we draw attention to the heterogeneous nature of the growth-exit relationship, which calls for more in-depth research. For policy makers, the implications are limited because our dataset does not allow for the identification of policy-induced growth. However, our findings provide policy makers input for a better understanding of firm growth policies.

\section{Acknowledgments}

We are grateful for the constructive inputs and comments provided by Jan de Kok. Previous versions (using different datasets and methods) have been presented at the ICSB 2011 in Stockholm, the IECER 2012 conference in Regensburg and the 2012 Babson College Entrepreneurship Research Conference, and published in the 2012 edition of Frontiers of Entrepreneurship Research. The authors are also grateful to useful feedback provided by the audiences of these conferences and to Joern Block and Evan Douglas for their helpful comments on earlier versions of this study. 


\section{References}

Acs, Z. J (2011), 'High-impact firms: gazelles revisited,' in M. Fritsch (ed), Handbook of Research on Entrepreneurship and Regional Development: National and Regional Perspectives. Edward Elgar Publishing: Cheltenham, pp. 133-174.

Acs, Z. J. and P. Mueller (2008), 'Employment effects of business dynamics: mice, gazelles and elephants,' Small Business Economics, 30(1), 85-100.

Agarwal, R. and D. B. Audretsch (2001), 'Does entry size matter? The impact of the life cycle and technology on firm survival,' Journal of Industrial Economics, 49(1), 21-43.

Almus, M. and E. Nerlinger (2000), 'Testing “Gibrat's law” for young firms - empirical results for West Germany,' Small Business Economics, 15(1), 1-12.

Audretsch, D. B., L. Klomp, E. Santarelli and A. R. Thurik (2004), 'Gibrat's law: are the services different?,' Review of Industrial Organization, 24(3), 301-324.

Audretsch, D. B. and T. Mahmood (1994), 'Firm selection and industry evolution: the post-FNtry performance of new firms,' Journal of Evolutionary Economics, 4(3), 243-260.

Audretsch, D. B. and T. Mahmood (1995), 'New firm survival: new results using a hazard function,' Review of Economics \& Statistics, 77(1), 97-103.

Becchetti, L. and G. Trovato (2002), 'The determinants of growth for small and medium sized firms: the role of the availability of external finance,' Small Business Economics, 19(4), 291-306.

Bigsten, A. and M. Gebreeyesus (2007), 'The small, the young, and the productive: determinants of manufacturing firm growth in Ethiopia,' Economic Development and Cultural Change, 55(4), 813-840.

Birch, D., A. Haggerty and W. Parsons (1995), Who's Creating Jobs? Cognetics Inc: Boston, MA.

Bottazzi, G. and A. Secchi (2003), 'Common properties and sectoral specificities in the dynamics of US manufacturing companies,' Review of Industrial Organization, 23(3/4), 217-232.

Calvo, J. L. (2006), 'Testing Gibrat's law for small, young and innovating firm,' Small Business Economics, 26(2), 117-123.

Capasso, M., E. Cefis and K. Frenken (2009), 'Do some firms persistently outperform?,' LEM Working Paper Series, No. 2009/15, Scuola Superiore Sant'Anna, Laboratory of Economics and Management (LEM), Pisa.

Capon, N., J. U. Farley and S. Hoenig (1990), 'Determinants of financial performance: a meta-analysis,' Management Science, 36(10), 1143-1159.

Cefis, E. and O. Marsili (2012), 'Going, going, gone. Exit forms and the innovative capabilities of firms,' Research Policy, 41(5), 795-807.

Coad, A. (2007), 'A closer look at serial growth rate correlation,' Review of Industrial Organization, 31(1), 69-82.

Coad, A., S. Daunfeldt, W. Hölzl, D. Johansson and P. Nightingale (2014a), 'High-growth firms: introduction to the special section,' Industrial and Corporate Change, 23(1), 91-112.

Coad, A., S. Daunfeldt, D. Johansson and K. Wennberg (2014b), 'Whom do high-growth firms hire?,' Industrial and Corporate Change, 23(1), 293-327.

Coad, A., J. Frankish, R. G. Roberts and D. J. Storey (2013), 'Growth paths and survival chances: an application of Gambler's Ruin theory,' Journal of Business Venturing, 28(5), 615-632.

Coad, A., J. S. Frankish, R. G. Roberts and D. J. Storey (2016a), 'Predicting new venture survival and growth: does the fog lift?,' Small Business Economics, 47(1), 217-241.

Coad, A. and W. Hölzl (2009), 'On the autocorrelation of growth rates,' Journal of Industry, Competition and Trade, 9(2), 139-166.

Coad, A. and W. Hölzl (2010), 'Firm growth: empirical analysis,' Papers on Economics and Evolution 2010-02, Max Planck Institute of Economics, Evolutionary Economics Group.

Coad, A., A. Segarra and M. Teruel (2016b), 'Innovation and firm growth: does firm age play a role?,' Research Policy, 45(2), 387-400.

Daunfeldt, S.-O. and D. Halvarsson (2015), 'Are high-growth firms one-hit wonders? Evidence from Sweden,' Small Business Economics, 44(2), 361-383.

Daunfeldt, S.-O., D. Halvarsson and D. Johansson (2015), 'Using the eurostat-OECD definition of high-growth firms: a cautionarynote,' Journal of Entrepreneurship and Public Policy, 4(1), 50-56.

Davidsson, P., L. Achtenhagen and L. Naldi (2005), 'Research on small firm growth: a review,' Proceedings of the European Institute of Small Business. pp. 1-28. $<$ Publisher name and location $>$

Davidsson, P. and M. Henrekson (2002), 'Determinants of the prevalence of start-ups and high-growth firms,' Small Business Economics, 19(2), 81-104.

Delmar, F. (1997), 'Measuring growth: methodological considerations and empirical results,' in R. Donckels and A. Miettinen (eds), Entrepreneurship and SME Research: On Its Way to the Next Millennium. Ashgate: Aldershot, UK and Brookfield, VA, pp. 190-216. 
Delmar, F., A. McKelvie and K. Wennberg (2013), 'Untangling the relationships among growth, profitability and survival in new firms,' Technovation, 33(8-9), 276-291.

Delmar, F. and J. Wiklund (2008), 'The effect of small business managers' growth motivation on firm growth: a longitudinal study,' Entrepreneurship Theory and Practice, 32(3), 437-457.

De Wit, G. and J. M. P. De Kok (2014), 'Do small businesses create more jobs? New evidence for Europe,' Small Business Economics, 42(2), 283-295.

DeTienne, D. R. and F. Chirico (2013), 'Exit strategies in family firms: how socioemotional wealth drives the threshold of performance,' Entrepreneurship Theory and Practice, 37(6), 1297-1318.

DeTienne, D. R., D. A. Shepherd and J. O. De Castro (2008), 'The fallacy of "only the strong survive": the effects of extrinsic motivation on the persistence decisions for under-performing firms,' Journal of Business Venturing, 23(5), 528-546.

Dunne, P. and A. Hughes (1994), 'Age, size, growth and survival: UK companies in the 1980s,' Journal of Industrial Economics, 42(2), 115-140.

Dunne, T., M. J. Roberts and L. Samuelson (1989), 'The growth and failure of U.S. manufacturing plants,' The Quarterly Journal of Economics, 104(4), 671-698.

Eisenhardt, K. M. and C. B. Schoonhoven (1990), 'Organizational growth: linking founding team, strategy, environment, and growth among U.S. semiconductor ventures, 1978-1988,' Administrative Science Quarterly, 35(3), 504-529.

European Commission (2010), Europe 2020: A Strategy for Smart, Sustainable and Inclusive Growth: Communication from the Commission. European Commission Publications Office: Brussels, Belgium.

Eurostat-OECD (2007), Eurostat-OECD Manual on Business Demography Statistics. Office for Official Publications of the European Communities: Luxembourg.

Garnsey, E. and P. Heffernan (2005), 'Growth setbacks in new firms,' Futures, 37(7), 675-697.

Garnsey, E., E. Stam and P. Heffernan (2006), 'New firm growth: exploring processes and paths,' Industry and Innovation, 13(1), $1-20$.

Geroski, P. A. (1995), Market Structure, Corporate Performance, and Innovative Activity. Oxford University Press: Oxford.

Geroski, P. A., J. Mata and P. Portugal (2010), 'Founding conditions and the survival of new firms,' Strategic Management Journal, 31(5), 510-529.

Gjerløv-Juel, P. and C. Guenther (2012), 'Heroes Today - But What about Tomorrow? Gazelles and Their Long-Term Performance (June 26, 2012),' http://ssrn.com/abstract $=2016798$.

Goddard, J., J. Wilson and P. Blandon (2002), 'Panel tests of Gibrat's law for Japanese manufacturing,' International Journal of Industrial Organization, 20(3), 415-433.

Greiner, L. (1972), 'Evolution and revolution as organization grow,' Harvard Business Review, 50, 37-46.

Greiner, L. (1998), 'Revolution is still inevitable,' Harvard Business Review, 76, 64-65.

Haans, R. F. J., C. Pieters and Z.-L. He (2016), 'Thinking about U: theorizing and testing U- and inverted U-shaped relationships in strategy research,' Strategic Management Journal, 37(7), 1177-1195.

Hambrick, D. and L. Crozier (1985), 'Stumblers and stars in the management of rapid growth,' Journal of Business Venturing, 1(1), 31-45.

Haveman, H. A. (1995), 'The demographic metabolism of organizations: industry dynamics, turnover, and tenure distributions,' Administrative Science Quarterly, 40(4), 586-618.

Helfat, C. E., S. Finkelstein, W. Mitchell, M. Peteraf, H. Singh, D. Teece and S. G. Winter (2007), Dynamic Capabilities: Understanding Strategic Change in Organizations. Blackwell: Malden, MA.

Henrekson, M. and D. Johansson (2010), 'Gazelles as job creators: a survey and interpretation of the evidence,' Small Business Economics, 35 (2), 227-244.

Hölzl, W. (2014), 'Persistence, survival, and growth: a closer look at 20 years of fast-growing firms in Austria,' Industrial and Corporate Change, 23(1), 199-231.

Jovanovic, B. (1982), 'Selection and the evolution of industry,' Econometrica, 50(3), 649-670.

Kogut, B. and U. Zander (1992), 'Knowledge of the firm, combinative capabilities, and the replication of technology,' Organization Science, 3(3), 383-397.

Levie, J. and B. B. Lichtenstein (2010), 'A terminal assessment of stages theory: introducing a dynamic states approach to entrepreneurship,' Entrepreneurship Theory and Practice, 34(2), 317-350.

Lockett, A., J. Wiklund, P. Davidsson and S. Girma (2011), 'Organic and acquisitive growth: re-examining, testing and extending Penrose's growth theory,' Journal of Management Studies, 48(1), 48-74.

Mata, J. and P. Portugal (1994), 'Life duration of new firms,' Journal of Industrial Economics, 42(3), 227-246.

McKelvie, A. and J. Wiklund (2010), 'Advancing firm growth research: a focus on growth mode instead of growth rate,' Entrepreneurship Theory and Practice, 34(2), 261-288.

McPherson, M. A. (1996), 'Growth of micro and small enterprise in Southern Africa,' Journal of Development Economics, 48(2), 253-277. 
Mitchell, W. (1994), 'The dynamics of evolving markets: the effects of business sales and age on dissolutions and divestures,' Administrative Science Quarterly, 39(4), 575-602.

Naldi, L. and P. Davidsson (2014), 'Entrepreneurial growth: the role of international knowledge acquisition as moderated by firm age,' Journal of Business Venturing, 29(5), 687-703.

OECD (2010), High-Growth Enterprises: What Government Can Do to Make a Difference. OECD: Paris, France.

Oliveira, B. and A. Fortunato (2008), 'The dynamics of the growth of firms: evidence from the services sector,' Empirica, 35(3), 293-312.

Pakes, A. and R. Ericson (1998), 'Empirical implications of alternative models of firm dynamics,' Journal of Economic Theory, 79(1), $1-45$.

Parker, S. C., D. J. Storey and A. van Witteloostuijn (2010), 'What happens to gazelles? The importance of dynamic management strategy,' Small Business Economics, 35(2), 203-226.

Penrose, E. (1995), The Theory of the Growth of the Firm, 3rd edn. Oxford University Press: Oxford.

Pierce, J. R. and H. Aguinis (2013), 'The too-much-of-a-good-thing effect in management,' Journal of Management, 39(2), 313-338.

Schumpeter, J. A. (1934), The Theory of Economic Development. Harvard University Press: Cambridge, MA.

Schutjens, V. A. and E. Wever (2000), 'Determinants of new firm success,' Papers in Regional Science, 79(2), $135-153$.

Sexton, D. L. and R. W. Smilor (1997), Entrepreneurship 2000. Upstart Publishing: Chicago.

Sharma, A. and I. Kesner (1996), 'Diversifying entry: some ex ante explanations for post-FNtry survival and growth,' Academy of Management Journal, 39(3), 635-677.

Shepherd, D. and J. Wiklund (2009), 'Are we comparing apples with apples or apples with oranges? Appropriateness of knowledge accumulation across growth studies,' Entrepreneurship Theory and Practice, 33(1), 105-123.

Sirmon, D. G., M. A. Hitt and R. D. Ireland (2007), 'Managing firm resources in dynamic environments to create value: looking inside the black box,' Academy of Management Review, 32(1), 273-292.

Sirmon, D. G., M. A. Hitt, R. D. Ireland and B. A. Gilbert (2011), 'Resource orchestration to create competitive advantage: breadth, depth, and life cycle effects,' Journal of Management, 37(5), 1390-1412.

Spearot, I. C. (2012), 'Firm heterogeneity, new investment and acquisitions,' Journal of Industrial Economics, 60(1), 1-45.

Sutton, J. (1997), 'Gibrat's legacy,' Journal of Economic Literature, 35(1), 40-59.

Törnqvist, L., P. Vartia and Y. O. Vartia (1985), 'How should relative changes be measured?,' The American Statistician, 39(1), 43-46.

Weinzimmer, L. G., P. C. Nystrom and S. J. Freeman (1998), 'Measuring organizational growth: issues, consequences and guidelines,' Journal of Management, 24(2), 235-262.

Wennberg, K., J. Wiklund, D. R. DeTienne and M. S. Cardon (2010), 'Reconceptualizing entrepreneurial exit: divergent exit routes and their drivers,' Journal of Business Venturing, 25(4), 361-375.

Yasuda, T. (2005), 'Firm growth, size, age and behavior in Japanese manufacturing,' Small Business Economics, 24(1), 1-15. 